\title{
Seasonal Modulation of Trapped Gravity Waves and Their Imprints on Trade Wind Clouds
}

\author{
Claudia Christine STEPHAN \\ Max Planck Institute for Meteorology, Hamburg, Germany
}

(Manuscript received 27 November 2019, in final form 9 June 2020)

\begin{abstract}
Shallow convection over the oceans is responsible for the largest uncertainties in climate projections. Idealized simulations have shown decades ago that shallow clouds generate internal gravity waves, which under certain atmospheric background conditions become trapped inside the troposphere and influence the development of clouds. These feedbacks, which occur at horizontal scales of up to several tens of kilometers. are neither resolved nor parameterized in traditional global climate models (GCMs), while the newest generation of GCMs (grid spacings $<5 \mathrm{~km}$ ) is starting to resolve them. The interactions between the convective boundary layer and trapped waves have almost exclusively been studied in highly idealized frameworks and it remains unclear to what degree this coupling affects the organization of clouds in the real atmosphere or in the new generation of GCMs. Here, the coupling between clouds and trapped waves is examined in $2.5-\mathrm{km}$ simulations that span the entirety of the tropical Atlantic and are initialized and forced with meteorological analyses. The coupling between clouds and trapped waves is sufficiently strong to be detected in these simulations of full complexity. Stronger upper-tropospheric westerly winds are associated with a stronger cloud-wave coupling. In the simulations this results in a highly organized scattered cloud field with cloud spacings of about $19 \mathrm{~km}$, matching the dominant trapped wavelength. Based on the large-scale atmospheric state, wave theory can reliably predict the regions and times where cloud-wave feedbacks become relevant to convective organization. Theory, the simulations, and satellite imagery imply a seasonal cycle in the trapping of gravity waves.
\end{abstract}

\section{Introduction}

Clouds are associated with some of the largest uncertainties in predicting the future evolution of climate (Boucher et al. 2013). For instance, the low-level cloud amount over the tropical oceans is one important factor for determining Earth's albedo (Cess 1976). The impact of clouds on the global radiation budget is critically affected by their interactions with the larger-scale circulation as well as with other clouds (Bony et al. 2015). Most global climate models (GCMs) cannot resolve the convective-scale organization of clouds and GCM parameterizations are not, and perhaps cannot be, designed to account for all relevant physical processes. Convective-scale organization and the vertical distribution of clouds are relevant for determining cloud radiative feedbacks (Soden and Vecchi 2011; Coppin and Bony 2018). A better understanding of convective-scale processes is desirable, as shallow moist convection is responsible for the largest contribution to the intermodel spread in climate sensitivity (Zhao 2014).

Corresponding author: Claudia Christine Stephan, claudia.stephan@mpimet.mpg.de
Dry and moist thermals in the convective boundary layer generate gravity waves (GWs) that propagate horizontally and vertically within the overlying stably stratified free troposphere. These convectively generated GWs are associated with vertical motions that can extend across the full depth of the troposphere. It has been known for several decades that convectively generated GWs influence the cloud spacing, the lifetime of clouds, and the likelihood of shallow convection to develop into deep convection. The relevant processes, which cause a positive reinforcement of convection, occur on horizontal scales shorter than several tens of kilometers (Clark et al. 1986; Balaji and Clark 1988; Hauf and Clark 1989; Lane and Clark 2002). These scales lie in between the scales of the typical widths of updrafts associated with shallow convection $(<1 \mathrm{~km})$ and large-scale vertical motion $(100-1000 \mathrm{~km})$. The latter is thought to condition the environment for the development of convection (Bony and Stevens 2019). The interactions between clouds and GWs are neither resolved in coarse GCMs, nor accounted for in convective parameterizations. The coupling between convective boundary layer dynamics and GWs has been studied relatively little, and then mostly in highly idealized 
contexts. It has not been established to what degree these processes matter in the real atmosphere or how well they are captured by models of full complexity, which are now run globally at convection-permitting resolution.

This study examines the coupling between clouds and GWs in simulations $(\Delta x=2.5 \mathrm{~km})$ spanning the entirety of the tropical Atlantic, initialized and forced with meteorological analyses. The following three questions are addressed: (i) Is the coupling between clouds and GWs sufficiently strong to be detectable also in situations that are not idealized to highlight its possible role? (ii) Can the large-scale atmospheric state be used to predict when and where coupling may be important for organizing convection? (iii) Is there a seasonal cycle in convectively generated GWs and their imprint on cloudiness?

An important factor controlling the properties of convectively generated GWs is the vertical shear of the horizontal wind, which varies from boreal summer, where it is small in the trade wind region, to winter, where it can be more pronounced. One of the first studies to examine the effects of different environmental profiles on the evolution of convective boundary layer eddies and the GW field was based on two-dimensional simulations of dry and moist convection with a model resolution of $125 \mathrm{~m}$ in the horizontal and vertical directions (Clark et al. 1986). At the early stage of the simulations the horizontal scale of the boundary layer thermals was only sensitive to the properties of the convective boundary layer itself. The boundary layer thermals generated internal GWs through mechanical as well as thermal forcing, which after some time filled the depth of the troposphere. These GWs showed typical characteristics of trapped waves, such as near-vertically aligned phase lines. The horizontal scales of the GWs were determined by the properties of the free troposphere. Their horizontal wavelength increased from $7.5 \mathrm{~km}$ near the bottom of the stably stratified free troposphere to $11 \mathrm{~km}$ just above the tropopause. At this stage the waves began to couple with the thermals to pattern the boundary layer convection following the scale of the overlying waves, doubling the original horizontal scale of the thermals. Clark et al. (1986) speculated that this layer interaction could be important for organizing the overall cloud spacing. The authors recognized that in some respects cloud initiation is a highly nonlocal problem. First, through the coupling to a wave field the clouds are able to communicate their presence to nearby clouds. Second, the properties of the upper troposphere or even the lower stratosphere determine whether GWs are trapped and can thereby influence the convective boundary layer.

Hauf and Clark (1989) repeated the Clark et al. (1986) study in three dimensions and confirmed many of the earlier findings. A scattered field of shallow clouds developed, which they interpreted as resulting from the competition between boundary layer rolls and GWs. Boundary layer rolls are oriented along the mean shear direction of the convective boundary layer, whereas the phase lines of convectively generated GWs are aligned normal to the mean shear direction of the stably stratified free troposphere. In their case the wind direction did not change and the two directions of alignment were orthogonal. Balaji and Clark (1988) prescribed a shear case where boundary layer rolls and convectively generated GWs aligned, creating banded structures of clouds. Their nonlinear simulations used a horizontal and vertical resolution of $1 \mathrm{~km}$ and $500 \mathrm{~m}$, respectively. Balaji and Clark (1988) pointed out that feedbacks between the convective boundary layer and the overlying wave field do not require a phase-locking between boundary layer thermals and the wave field. When the wave field and the boundary layer thermals are moving relative to each other, then the cloud spacing is still set by the wavelength of the overlying wave field. Meanwhile, the difference in translation speeds defines the life cycle and depth of convection.

The modal characteristics of the stably stratified free troposphere determine the dominant horizontal scales of GWs. Through a detailed linear analysis of two-dimensional simulations with different background wind profiles Lane and Clark (2002) attributed the horizontal-scale selection to a combination of two processes: dissipation through critical-level filtering, which occurs when the ground-based phase speed of downstream-propagating GWs matches the wind speed, and the trapping of upstream-propagating waves. As a consequence, waves propagating in a direction parallel to the mean shear vector in the free troposphere have the greatest likelihood of being dissipated or trapped. Thus, the phase speed spectrum experiences the greatest asymmetry in the direction of the shear vector. Lane and Clark (2002) confirmed the resonant interaction between boundary layer thermals and trapped GWs. This study focuses on trapped GWs.

The manuscript is organized as follows. Numerical simulations and satellite data are described in section 2 . Section 3 discusses the seasonal variability of the largescale circulation, the simulated variability of trapped GWs, the coupling between waves and clouds in the simulations and gives examples of the imprints of waves on the cloud field. Section 4 contains a summary and conclusions.

\section{Numerical and observational data}

\section{a. Numerical simulations}

We analyze simulations of the Icosahedral Nonhydrostatic (ICON) model that were run over a domain spanning the tropical Atlantic (Fig. 1). A detailed description of 


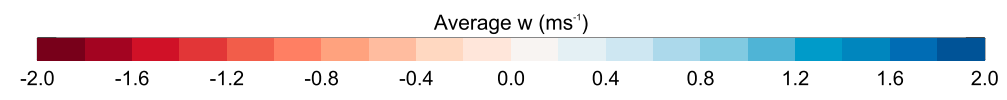

(a) $2013-12$

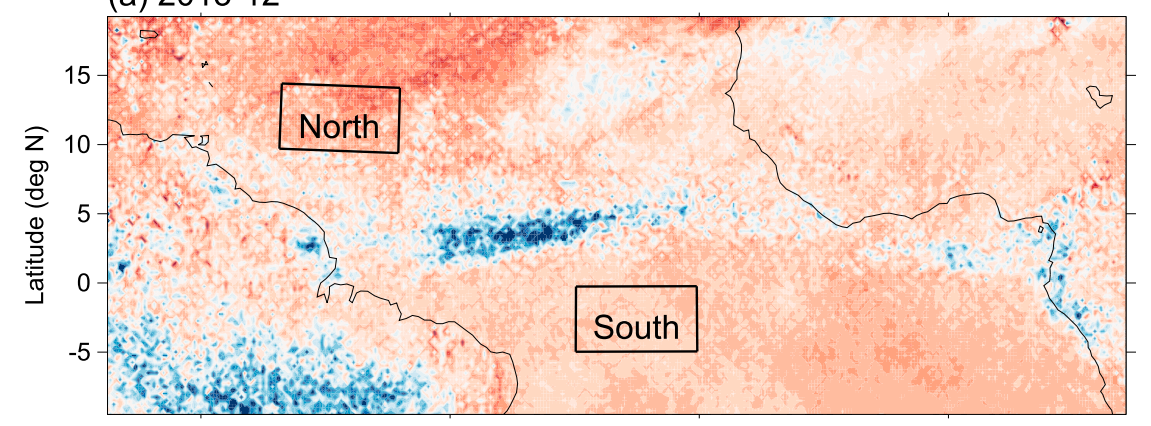

(b) 2016-08

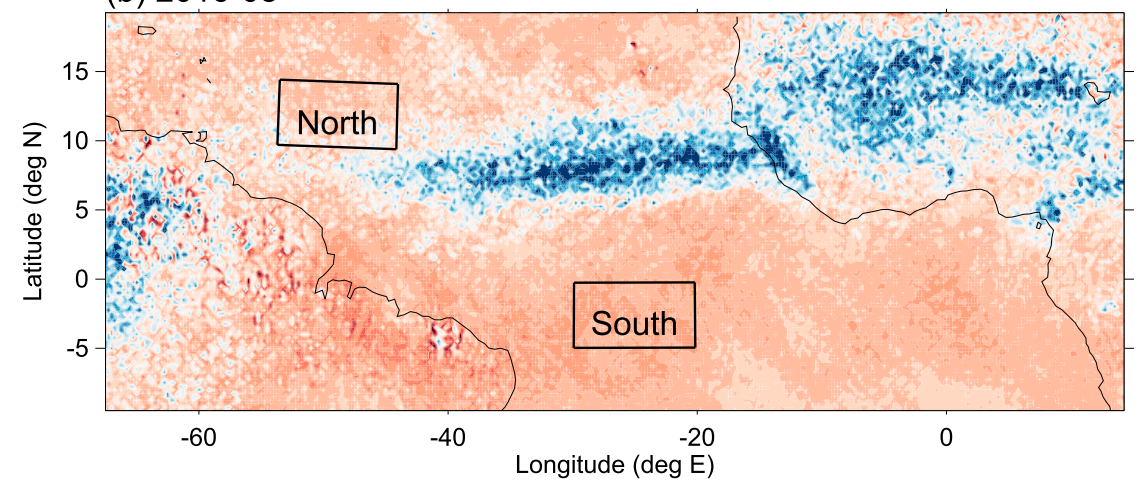

FIG. 1. Average simulated (a) December and (b) August vertical velocity at $5 \mathrm{~km}$ altitude over the full domain of the simulation. Black boxes show the subdomains that are analyzed. The North domain is located at $10^{\circ}$ to $15^{\circ} \mathrm{N},-55^{\circ}$ to $-45^{\circ} \mathrm{E}$ and the South domain at $-5^{\circ}$ to $0^{\circ} \mathrm{N},-30^{\circ}$ to $-20^{\circ} \mathrm{E}$.

these simulations and how to access them can be found in Klocke et al. (2017). The triangular grid has a spacing of about $2.4 \mathrm{~km}$. Convective parameterizations are turned off. Only turbulence, cloud microphysics, and radiation are parameterized. The horizontal resolution that we selected for this study is much coarser than in previous idealized experiments. At this grid spacing large turbulent eddies, as they appear in reality, cannot be resolved. However, the simulations do produce organized vertical motion at scales on the order of $10 \mathrm{~km}$, which is able to force GWs. Such kilometerresolution models mark an important step in the history of global modeling as they begin to resolve moist convection in the context of global dynamics, without relying on cumulus parameterizations. A critical evaluation of processes that are just starting to be resolved, such as small-scale GWs in the troposphere, is therefore important and motivates us to analyze simulations with kilometer resolution.

Two sets of simulations are available: one of the full month of December 2013 and one of the full month of August 2016. On each day the model was initialized at
0000 UTC with data from the atmospheric analysis of the European Centre for Medium-Range Weather Forecasts (ECMWF) and integrated for $36 \mathrm{~h}$ with boundary data from 3-hourly ECMWF forecasts. We discard the first $12 \mathrm{~h}$ of each simulation to avoid spinup effects. The overall setup of the simulations guarantees that the large-scale atmospheric state is realistic. This is an important benefit because GWs are sensitive to the large-scale wind and temperature profiles (see section 3a for more details). The realism of the atmospheric state allows a comparison of individual days with observations.

Our analysis is based on the three-dimensional wind, pressure, and temperature fields, available every hour, as well as vertically integrated cloud water and surface precipitation, available every $30 \mathrm{~min}$. All data are first regridded to a horizontal grid of $0.025^{\circ} \times 0.025^{\circ}$ resolution in longitude and latitude. Three-dimensional data are vertically interpolated to constant-height levels with a $350 \mathrm{~m}$ spacing, which corresponds to the average vertical grid spacing in the midtroposphere $(5-10 \mathrm{~km})$. 
We select two subdomains, the domain "North" at $10^{\circ}-15^{\circ} \mathrm{N}, 55^{\circ}-45^{\circ} \mathrm{W}$ and the domain "South" at $5^{\circ}-0^{\circ} \mathrm{S}$, $30^{\circ}-20^{\circ} \mathrm{W}$. These subdomains represent oceanic areas where large-scale subsidence prevails in December as well as in August (Fig. 1). The large-scale atmospheric circulation in the regions is affected by the migration of the ITCZ (Stevens et al. 2016), which allows an assessment of the sensitivity of GW trapping to the seasonal cycle. Areas of large-scale subsidence are favorable for the development of shallow cumulus convection and therefore suitable for our attempt to identify cloud-wave coupling, which elsewhere would likely be masked by strong perturbations from deep convection. The meridional boundaries are located away from the edge of the simulation to avoid potential unphysical influences from the boundary conditions.

\section{b. Satellite observations}

Based on the simulations we identify days with particularly strong and ubiquitous trapping of GWs. To test if trapped waves were also present in reality, we consult satellite imagery from the Moderate Resolution Imaging Spectroradiometer (MODIS) instruments aboard the Terra and Aqua satellites. We show true-color corrected-reflectance imagery (Gumley et al. 2010) from NASA's Worldview application (https://worldview.earthdata.nasa.gov). Their algorithm is based on level $1 \mathrm{~B}$ data of calibrated and geolocated radiances and combines the MODIS visible bands $1-7$. The temporal resolution is daily, covering 24 February 2000-present (Terra) and 3 July 2002-present (Aqua). The sensor resolution is $500 \mathrm{~m}$ (bands 3-7) and $250 \mathrm{~m}$ (bands 1 and 2). The resolution of the original images available online is much higher than displayed in this manuscript and we encourage the reader to browse the original imagery online.

\section{Results}

\section{a. Variability of large-scale conditions}

Background winds and stability determine if GWs are able to propagate into the stratosphere or become trapped in the troposphere. Even though the assumptions of linear theory, such as horizontal homogeneity and no rotation, are violated here, it is insightful to consider the Taylor-Goldstein equation, which describes linear disturbances in a stably stratified atmosphere in two dimensions, cf. Nappo (2002),

$$
\frac{d^{2} \hat{w}}{d z^{2}}+\left(S^{2}-k_{x}^{2}\right) \hat{w}=0
$$

where $\hat{w}=e^{-z / 2 H_{s}} w$ is the vertical velocity component $w$ weighted by density, $H_{s}$ is the density scale height, $k_{x}$ is the horizontal wavenumber, and $S^{2}$ is the Scorer parameter:

$$
S^{2}=\underbrace{\frac{N^{2}}{(c-U)^{2}}}_{\mathrm{T} 1} \underbrace{+\frac{1}{(c-U)} \frac{d^{2} U}{d z^{2}}}_{\mathrm{T} 2} \underbrace{-\frac{1}{H_{s}(c-U)} \frac{d U}{d z}}_{\mathrm{T} 3} \underbrace{-\frac{1}{4 H_{s}}}_{\mathrm{T} 4} .
$$

The horizontal phase speed is $c$ and $U$ is the projection of the horizontal wind along the horizontal wave vector. For waves that are able to propagate upward across a layer of small $S^{2}$, the factor $\left(S^{2}-k_{x}^{2}\right)$ needs to be positive, which requires the horizontal wavelength $\lambda_{x}=$ $2 \pi / k_{x}$ to be greater than the critical wavelength $\lambda_{x}^{*}$ :

$$
\lambda_{x}>\lambda_{x}^{*}=\frac{2 \pi}{S} .
$$

Waves with $\lambda_{x}<\lambda_{x}^{*}$ have imaginary vertical wavenumbers, $m^{2}<0$, outside of the region where they can propagate, and are trapped. Above the trapping level, their amplitudes decay exponentially and at the trapping level the vertical wavenumber becomes zero. The phase lines of trapped waves are orientated vertically (Lane and Clark 2002).

An additional property of trapped waves is that their intrinsic frequency $\hat{\omega}=\omega-U k_{h}$ exceeds the local BruntVäisälä frequency $N$. This can occur, for instance, through a Doppler shift of the ground-based frequency $\omega$ when a wave propagates upstream $\left(-U k_{h}>0\right)$. The criteria $\hat{\omega}>N$ and $m^{2}<0$ are related, as is seen from the GW dispersion relation in the high-frequency limit,

$$
m^{2}=k_{h}^{2}\left(\frac{N^{2}}{\hat{\omega}^{2}}-1\right) \text {. }
$$

Conditions conducive to trapping are characterized by $\lambda_{x}^{*}$ increasing with height, or equivalently, by the Scorer parameter decreasing with height. To ascertain the likeliness of trapping, we now examine profiles of the BruntVäisälä frequency and the zonal winds within the North and South domains (Fig. 2).

The profiles of buoyancy are similar between the two domains (Figs. 2a,b). They show a peak at around $1.5 \mathrm{~km}$, which marks the trade wind inversion. The August profiles show a second maximum at about 5$6 \mathrm{~km}$, which is associated with the melting layer. The minimum in the buoyancy frequency is found at about $10 \mathrm{~km}$.

Figures $2 \mathrm{c}$ and $2 \mathrm{~d}$ compare monthly and domainmean vertical profiles of the zonal wind between December and August. In the North domain August zonal winds are nearly constant at about $-5 \mathrm{~m} \mathrm{~s}^{-1}$ from the surface up to $15 \mathrm{~km}$. December winds, in contrast, 
(a) North buoyancy frequency

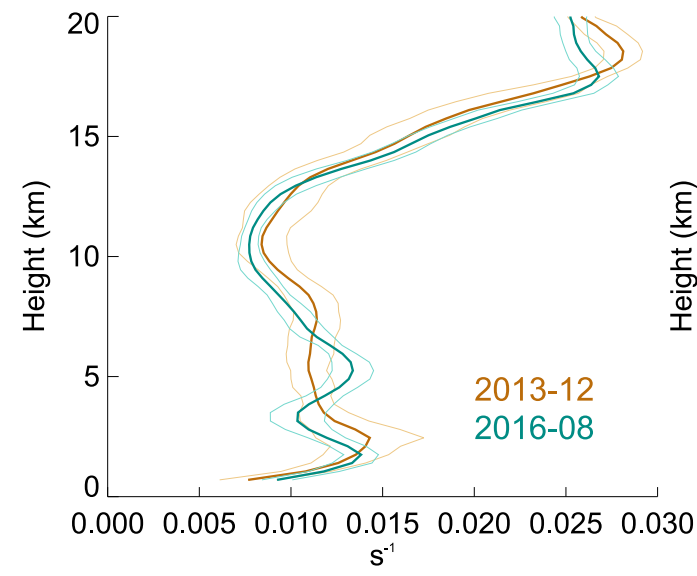

(c) North zonal wind

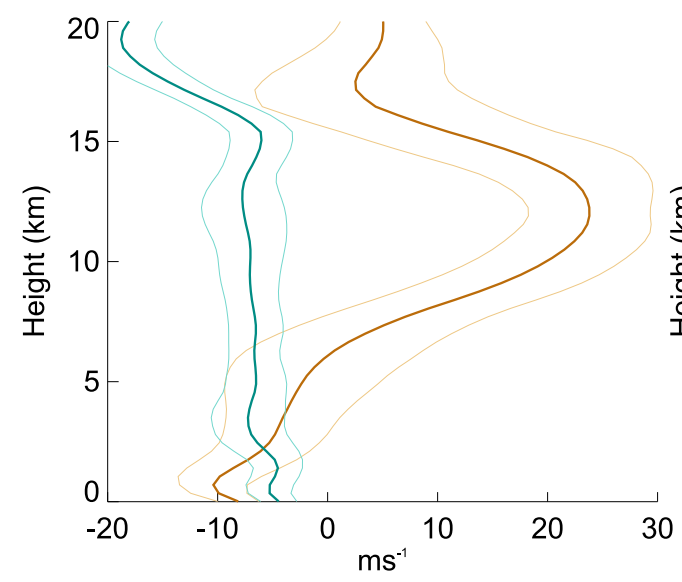

(e) North meridional wind

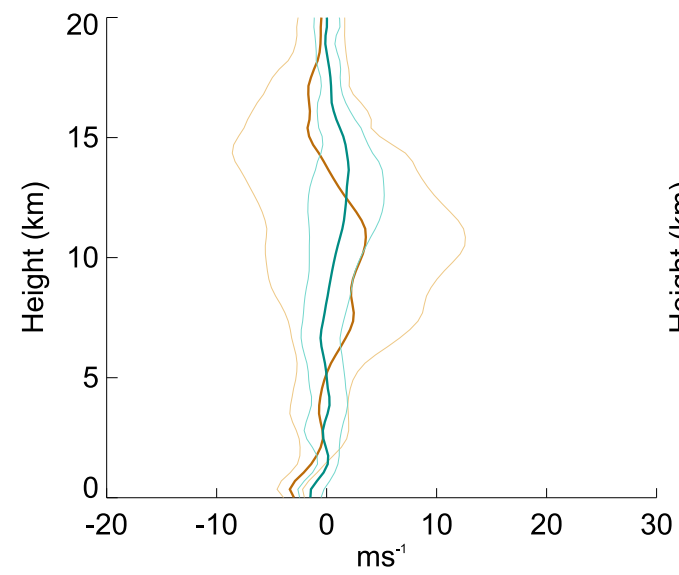

(b) South buoyancy frequency

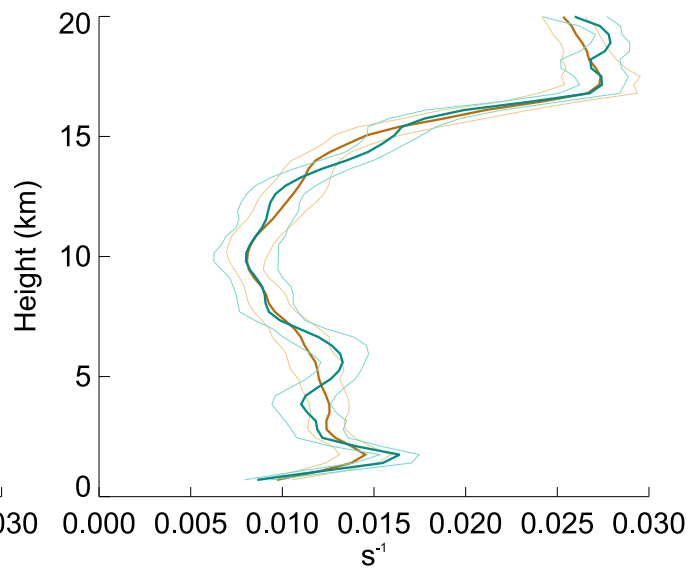

(d) South zonal wind

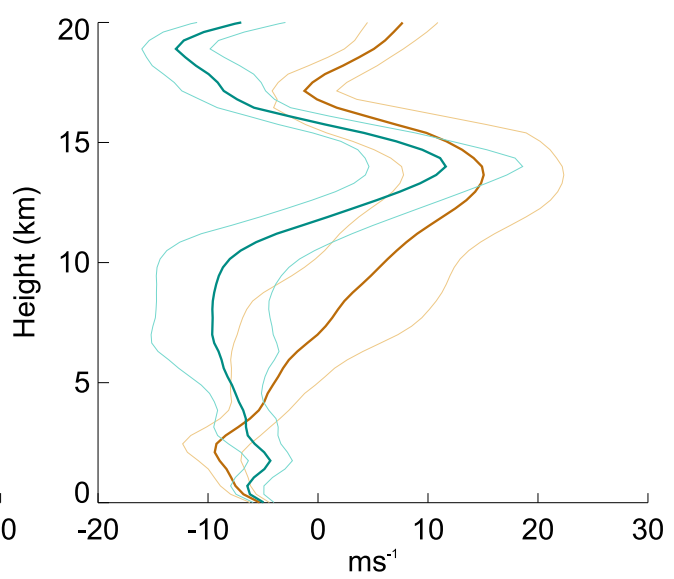

(f) South meridional wind

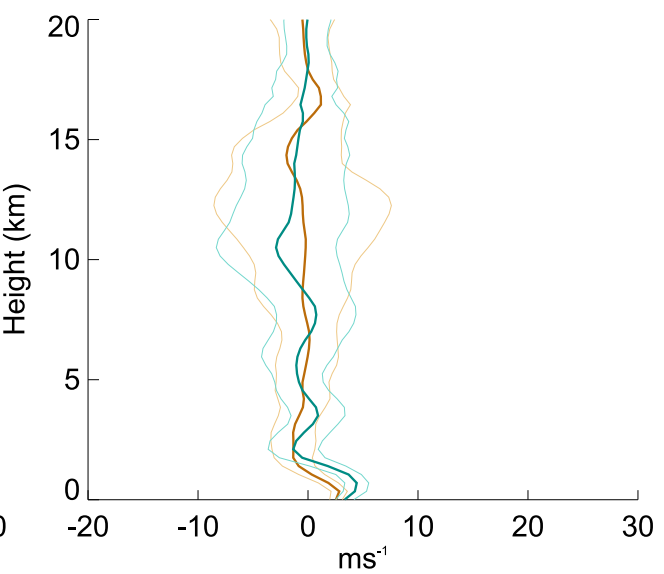

FIG. 2. Monthly and domain-mean vertical profiles of the (a),(b) buoyancy frequency, (c),(d) zonal wind, and (e),(f) meridional wind for the (a),(c),(e) North and (b),(d),(f) South domains. Thin lines show \pm 1 standard deviation computed from daily domain-mean data. 

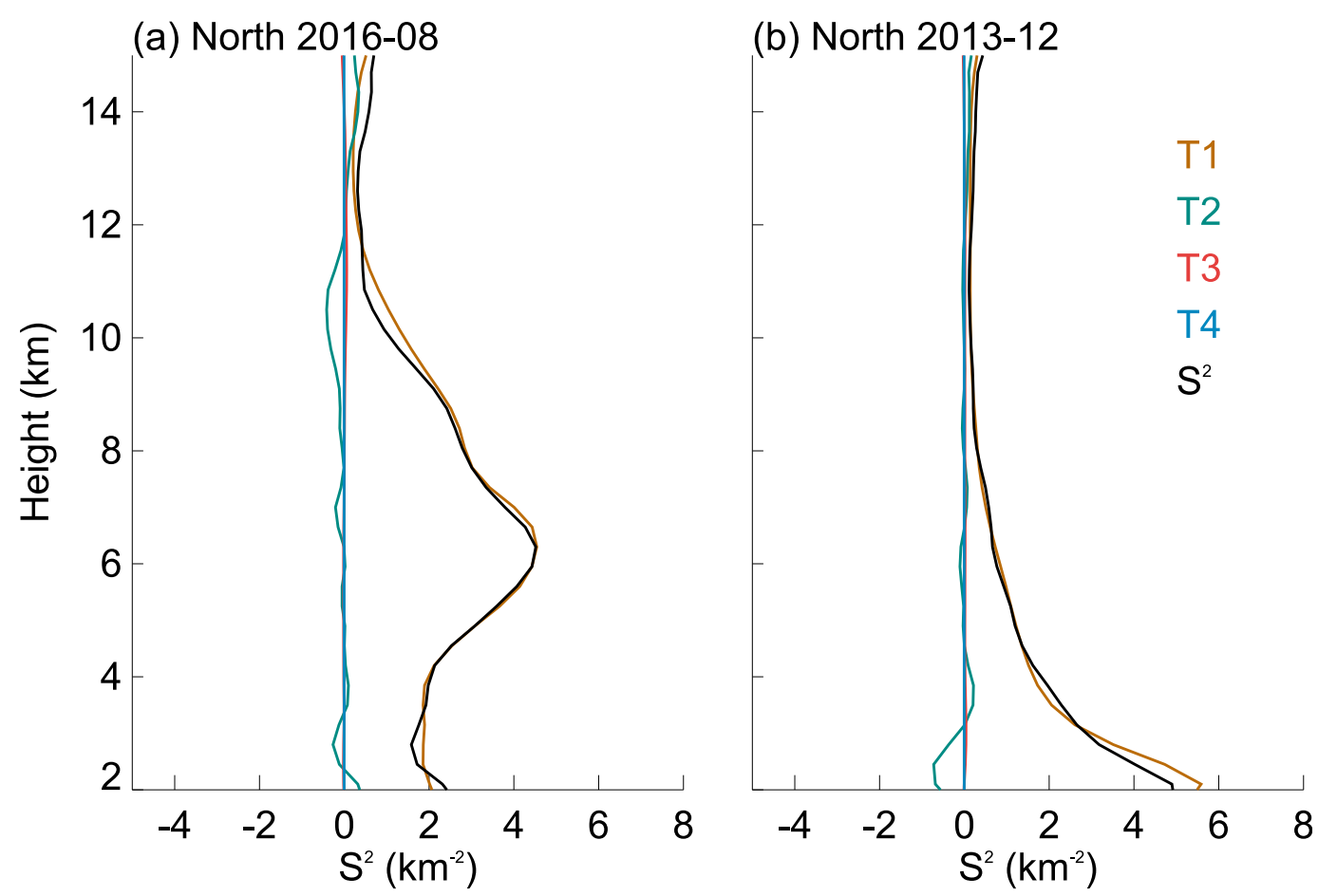

FIG. 3. Effects of the seasonal cycle on the Scorer parameter. Shown are the Scorer parameter $S^{2}$ (black) and the contributions of the different terms defined in Eq. (2) for a wave propagating at a ground-based phase speed of $-15 \mathrm{~m} \mathrm{~s}^{-1}$ in the zonal direction. Derivations use monthly mean and domain-mean atmospheric background conditions in (a) August and (b) December.

turn from easterlies of about $-10 \mathrm{~m} \mathrm{~s}^{-1}$ near the surface to westerlies exceeding $20 \mathrm{~m} \mathrm{~s}^{-1}$ at $12 \mathrm{~km}$ altitude. In the South domain, strong wind shear is present above $10 \mathrm{~km}$ in August. In December shear is present throughout the troposphere, increasing from $-10 \mathrm{~m} \mathrm{~s}^{-1}$ near the surface to about $+10 \mathrm{~m} \mathrm{~s}^{-1}$ at $12 \mathrm{~km}$ altitude.

The profiles confirm a strong seasonal change. August is less favorable for trapping than December, because the Scorer parameter does not decrease as strongly with height, as is seen in the example shown in Fig. 3. The lines in Fig. 3 show the Scorer parameter $S^{2}$ in black and its individual terms in colors for a wave propagating upstream at a ground-based phase speed of $-15 \mathrm{~m} \mathrm{~s}^{-1}$, a typical speed for tropospheric GWs (e.g., Lane and Clark 2002; Stephan et al. 2016). In section 3c we will see that zonal winds at $5-10 \mathrm{~km}$ are relevant for cloudwave coupling during December in the North domain (Table 2). The typical wind speed at $10 \mathrm{~km}$ altitude is $20 \mathrm{~m} \mathrm{~s}^{-1}$ (Fig. 2c), resulting in $(U-c)=35 \mathrm{~m} \mathrm{~s}^{-1}$. Using the expression for T1 with $N=0.012 \mathrm{~s}^{-1}$, we can estimate the horizontal wavelength to be $\sim 18 \mathrm{~km}$. We will see that this is indeed very close to the peak wavelengths in the North domain (Table 1), which shows that a phase speed of $-15 \mathrm{~m} \mathrm{~s}^{-1}$ is a consistent choice for the purpose of our present discussion.

$\mathrm{T} 1$ is at most altitudes several orders of magnitude greater than the other terms. T2, the curvature term, can

TABLE 1. Domain- and time-averaged power-weighted peak zonal wavelengths with their standard deviations. Standard deviations are computed from daily data of domain averages.

\begin{tabular}{lcccc}
\hline \hline & \multicolumn{2}{c}{ North } & & South \\
\cline { 2 - 5 } & August 2016 & December 2013 & August 2016 & December 2013 \\
\hline$\left\langle\lambda_{w}^{p}\right\rangle$ at $14 \mathrm{~km}$ & $26.3 \pm 3.4$ & $26.5 \pm 1.6$ & $26.9 \pm 3.8$ & $27.1 \pm 3.3$ \\
$\left\langle\lambda_{w}^{p}\right\rangle$ at $7 \mathrm{~km}$ & $17.2 \pm 3.6$ & $21.3 \pm 2.8$ & $26.3 \pm 1.9$ & $24.3 \pm 3.6$ \\
$\left\langle\lambda_{w}^{p}\right\rangle$ at $3.5 \mathrm{~km}$ & $15.4 \pm 2.0$ & $19.0 \pm 2.3$ & $21.5 \pm 1.9$ & $19.9 \pm 3.2$ \\
$\left\langle\lambda_{w}^{p}\right\rangle$ at $1.75 \mathrm{~km}$ & $14.3 \pm 1.0$ & $16.9 \pm 1.0$ & $14.3 \pm 1.0$ & $15.1 \pm 2.4$ \\
$\left\langle\lambda_{c}^{p}\right\rangle$ & $16.0 \pm 1.1$ & $18.9 \pm 1.6$ & $18.0 \pm 1.1$ & $18.6 \pm 1.3$ \\
\hline
\end{tabular}


(a) North 2013-12 rank correlations $>0.5$

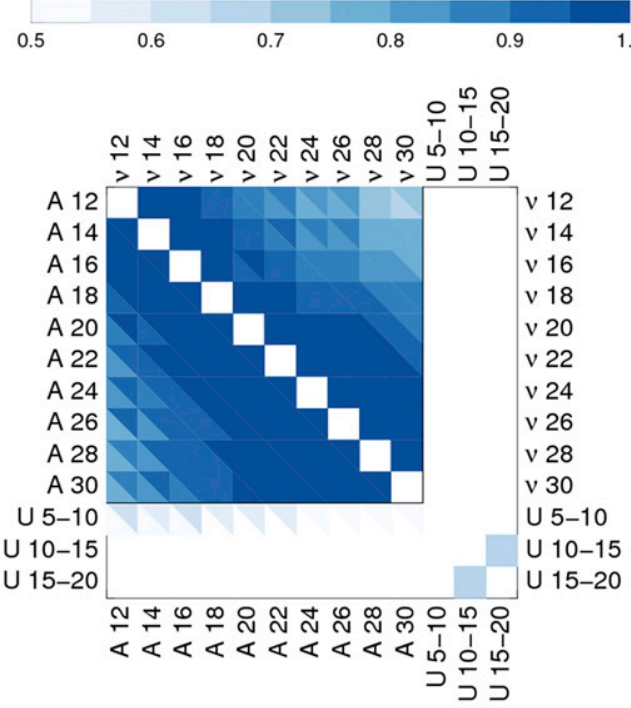

(c) North $2016-08$ rank correlations $>0.5$

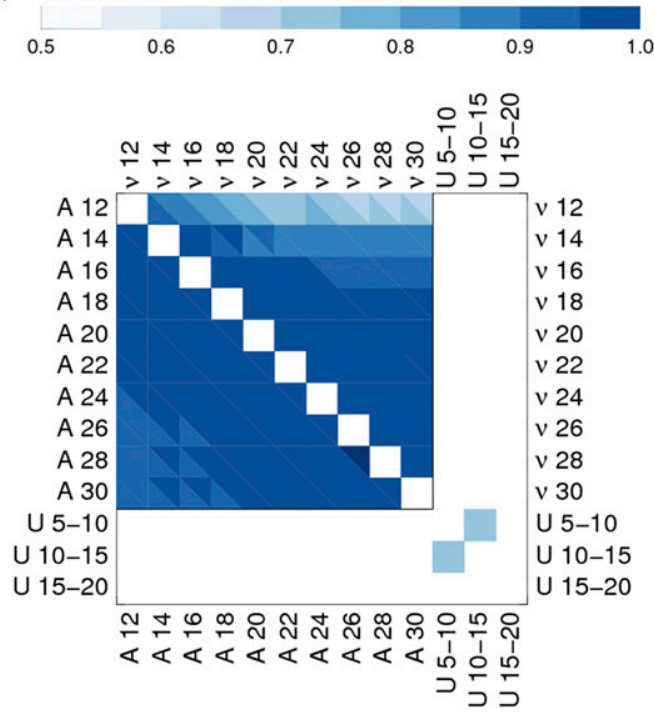

(b) South 2013-12 rank correlations $>0.5$

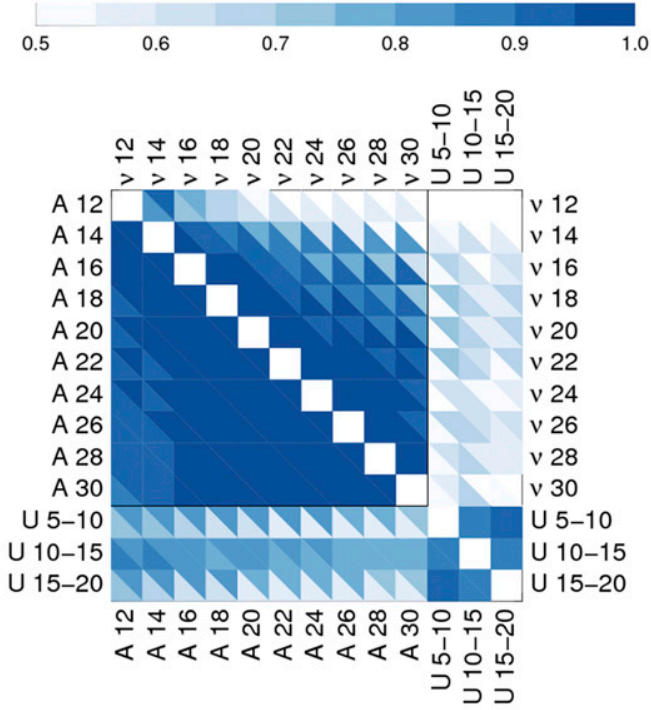

(d) South 2016-08 rank correlations $>0.5$

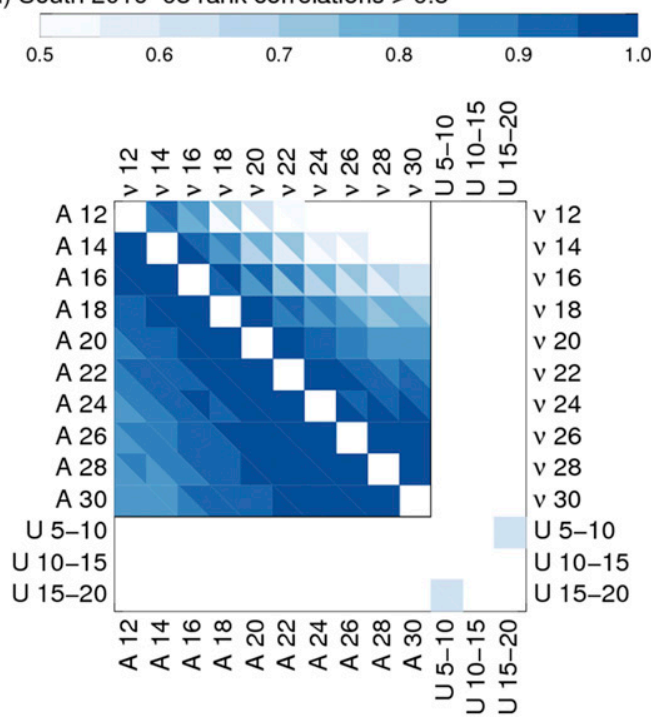

FIG. 4. Colors show Spearman's rank correlation coefficients between pairs of daily time series, which are labeled on the sides. The time series include the trapping amplitudes $\left.A_{\text {trap }}\right|_{z_{\text {ref }}, \lambda_{x}}$, the trapping frequencies $\left.\nu_{\text {trap }}\right|_{z_{\text {ref }}, \lambda_{x}}$, and domain-mean zonal winds $U$. Numbers in these labels are in units of $\mathrm{km}$ and they denote wavelengths (for $\nu_{\text {trap }}$ and $\left.A_{\text {trap }}\right)$ or altitude ranges for averaging $(U)$. Labels at the bottom and on the left pertain to the bottom-left half of each panel. Labels at the top and on the right pertain to the top-right half of each panel. All correlations use time series at a fixed $z_{\text {ref }}$. For each pair of variables the correlation coefficient for $z_{\text {ref }}=3.5 \mathrm{~km}$ is shown in the bottom-left triangle and the $z_{\text {ref }}=7 \mathrm{~km}$ value is shown in the top-right triangle.

get large if there is a strong jet aloft. T3 includes the wind shear term $d U / d z$. Wind shear is responsible for the seasonal variability in the Scorer parameter. However, it is not $\mathrm{T} 3$ that makes the difference, but the denominator of $\mathrm{T} 1,(c-U)^{2}$. The shear is implicit in $\mathrm{T} 1$ in the sense that $U=U(z)$ and hence vertical variability in $U$ translates into vertical variability in $\mathrm{T} 1$.

All of the following computations, including those of horizontal spectra, are performed in the zonal direction, ignoring the meridional wind component. This simplification is well justified because the mean meridional wind is nearly zero with the exception of the lowest few kilometers (Figs. 2e,f).

\section{b. Variability of trapped GWs in simulations}

We use the one-dimensional S-transformation (Stockwell et al. 1996) to extract localized distance-wavenumber information from the model output. This technique is an 
TABLE 2. Spearman's rank correlations $R$ between the daily index of cloud-wave coupling $\nu_{\text {coupl }}$ and the zonal wind speed $U$ or the Scorer parameter $S^{2}$ at different altitudes. Only correlations $>0.5$ are shown. The Scorer parameter is computed for ground-based phase speeds of $0 \mathrm{~m} \mathrm{~s}^{-1}$.

\begin{tabular}{lcccc}
\hline \hline & \multicolumn{2}{c}{ North } & \multicolumn{2}{c}{ South } \\
\cline { 2 - 5 }$R$ of $\nu_{\text {coupl }}$ with & August 2016 & December 2013 & August 2016 & December 2013 \\
\hline$U$ at $5-10 \mathrm{~km}$ & - & 0.58 & - & 0.80 \\
$U$ at $10-15 \mathrm{~km}$ & - & - & - & 0.87 \\
$U$ at $15-20 \mathrm{~km}$ & - & -0.57 & - & 0.75 \\
$S^{2}$ at $5-10 \mathrm{~km}$ & - & - & - & -0.82 \\
$S^{2}$ at $10-15 \mathrm{~km}$ & & & & \\
\hline
\end{tabular}

extension of a continuous wavelet transformation and provides spectral information at each spatial location. It uses sinusoidal functions that are modulated by a Gaussian whose width is inversely proportional to the wavelength. The Gaussian window is translated along the spatial dimension to obtain localized spectral information. This spectral analysis tool has been extensively used for characterizing GWs in different datasets (e.g., Wang et al. 2006; Alexander et al. 2008; Fritts et al. 2012; Wright and Gille 2013).

In the following, $\lambda_{w}^{p}$ and $\lambda_{c}^{p}$ denote the daily mean peak zonal wavelengths of the vertical velocity and the cloud field, respectively. Details of the derivation are shown in the appendix section a. Monthly means are denoted $\left\langle\lambda_{w}^{p}\right\rangle$ and $\left\langle\lambda_{c}^{p}\right\rangle$. Table 1 shows the results at selected altitudes. $\left\langle\lambda_{w}^{p}\right\rangle$ increases with altitude, as was also found in previous idealized studies (Clark et al. 1986; Balaji and Clark 1988; Lane and Clark 2002). In December, but not in August, there exist negative correlations between the domainand daily-mean peak wavelength, $\lambda_{w}^{p}$, at $7 \mathrm{~km}$ and the strength of the background wind at different levels. The Spearman's rank correlations exceeding 0.5 of $\lambda_{w}^{p}$ at $7 \mathrm{~km}$ are in the North domain -0.57 for $U$ averaged over $15-20 \mathrm{~km}$ altitude, and in the South domain -0.74 for $U$ at $15-20$ and $10-15 \mathrm{~km}$ and -0.81 for $U$ at $5-10 \mathrm{~km}$. These correlations show that $\lambda_{w}^{p}$ decreases with increasing winds, which is consistent with the influence of the winds on the critical horizontal wavelength that we would expect from theory. When the critical wavelength becomes large, more short waves are trapped and $\lambda_{w}^{p}$ decreases.

Table 1 shows furthermore that $\left\langle\lambda_{c}^{p}\right\rangle$ is close to $\left\langle\lambda_{w}^{p}\right\rangle$ in the lower troposphere. This is not proof, but a necessary criterion for a positive reinforcement between waves and convection, as it allows the periodic up- and downdrafts to align with the periodic vertical motion associated with the wave field. The scales of $\left\langle\lambda_{c}^{p}\right\rangle$ and $\left\langle\lambda_{w}^{p}\right\rangle$ are similar to the $15-30 \mathrm{~km}$ cloud spacing that was observed during the GATE phase III experiment in the eastern tropical Atlantic (LeMone and Meitin 1984). During GATE phase III, the mean shear in the boundary layer was perpendicular to the shear in lower troposphere, a situation conducive to line organization (section 1). Balaji et al. (1993) showed that this scale selection of banded clouds was very likely influenced by the presence of a deep GW mode.

Trapped GWs are characterized by nearly vertically aligned phase lines. We use this property to identify instances of trapping in space and time. Details of the cross-spectral analysis are given in appendix section $b$. For zonal wavelengths $\lambda_{x} \in\{12,14,16,18,20,22,24,26$, $28,30\} \mathrm{km}$ the daily trapping fraction $\nu_{\text {trap }}$ is the daily mean of the fraction of the domain where the spectral component $\lambda_{x}$ of the vertical velocity field is vertically aligned with respect to a reference level $z_{\text {ref }}$. We use two reference levels: $z_{\text {ref }}=3.5 \mathrm{~km}$ and $z_{\text {ref }}=7 \mathrm{~km}$. The reference levels are selected to be in the lower and midsection of the free troposphere as this is where we expect to find trapped waves. We use two instead of one reference level to increase robustness. The corresponding averaged covarying amplitude of the vertical velocity field is denoted $A_{\text {trap }}$.

Figure 4 shows Spearman's rank correlations between daily- and domain-mean time series of $A_{\text {trap }}$ for all pairs of $\lambda_{x}$ (lower-left half in each panel), and those between $\nu_{\text {trap }}$ (upper-right half in each panel). All correlations use time series at a fixed $z_{\text {ref. }}$ For each pair of wavelengths, the correlation coefficient for $z_{\text {ref }}=3.5 \mathrm{~km}$ is shown in the bottom left triangle and the $z_{\text {ref }}=7 \mathrm{~km}$ value is shown in the top right triangle. We also report the Spearman's rank correlations between $A_{\text {trap }}$ and zonal winds at 5-10, 10-15 and 15-20 km (bottom three rows of each panel), and between $\nu_{\text {trap }}$ and zonal winds (rightmost three columns in each panel). Blue colors indicate Spearman's rank correlations exceeding 0.5.

The dark colors in the vicinity of the diagonal imply that if one wavelength is trapped, then nearby ones are, too. This is expected from theory and shows that the time series we defined are robust. Stronger westerly winds in December at $5-10 \mathrm{~km}$ are associated with stronger covarying vertical velocity amplitudes in both domains (Figs. 4a,b). In the South domain this effect is more 


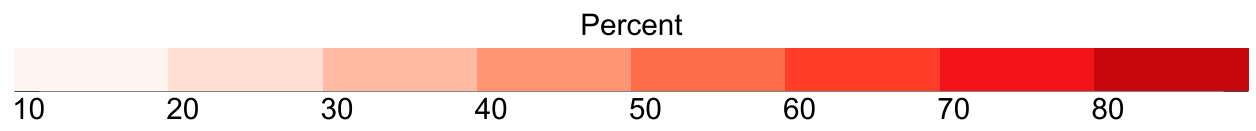

(a) North 2013-12

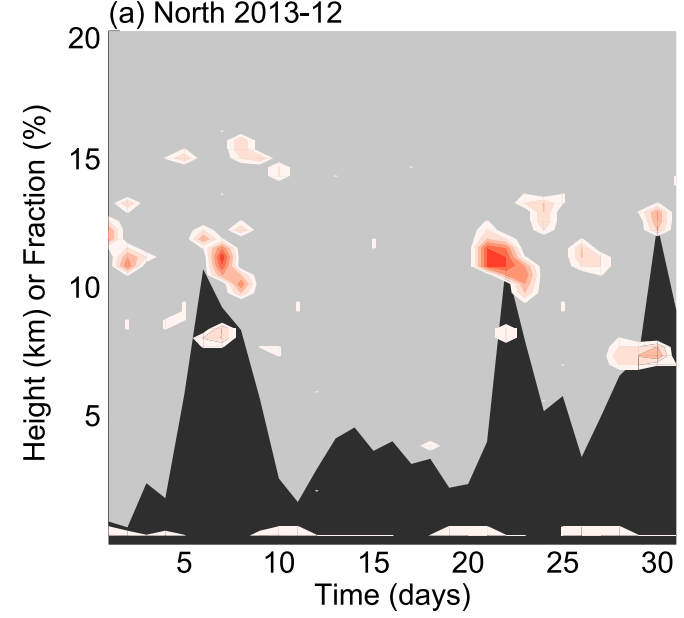

(c) North 2016-08

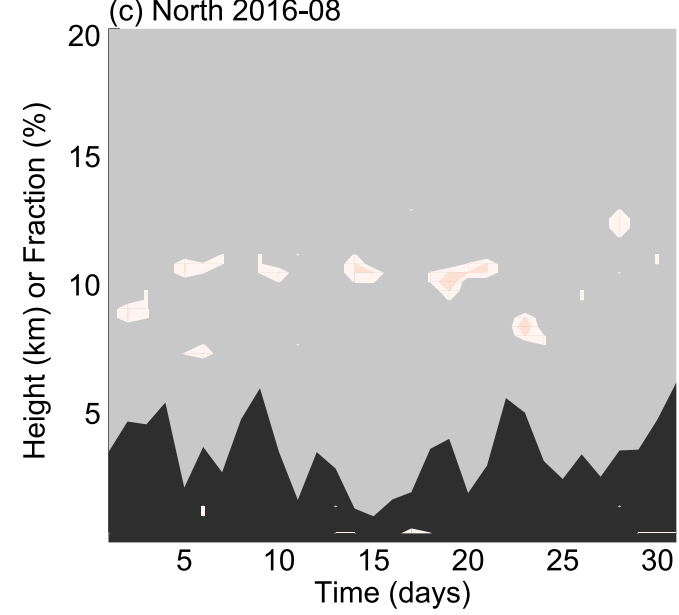

(b) South 2013-12

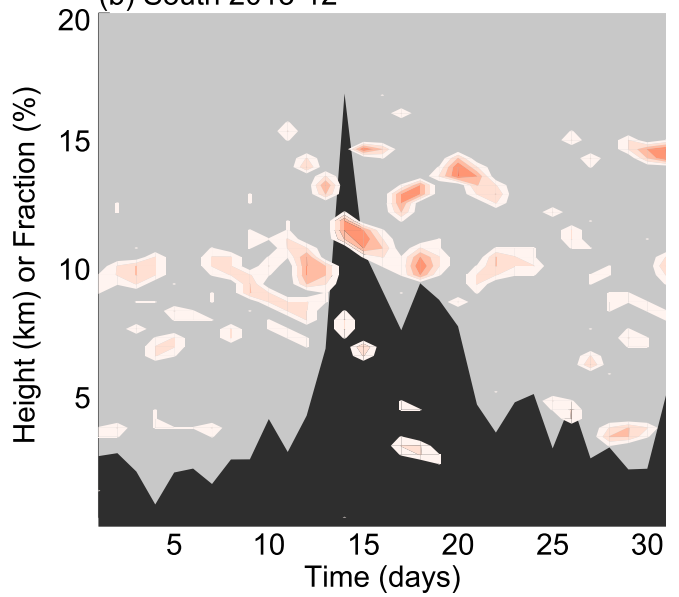

(d) South 2016-08

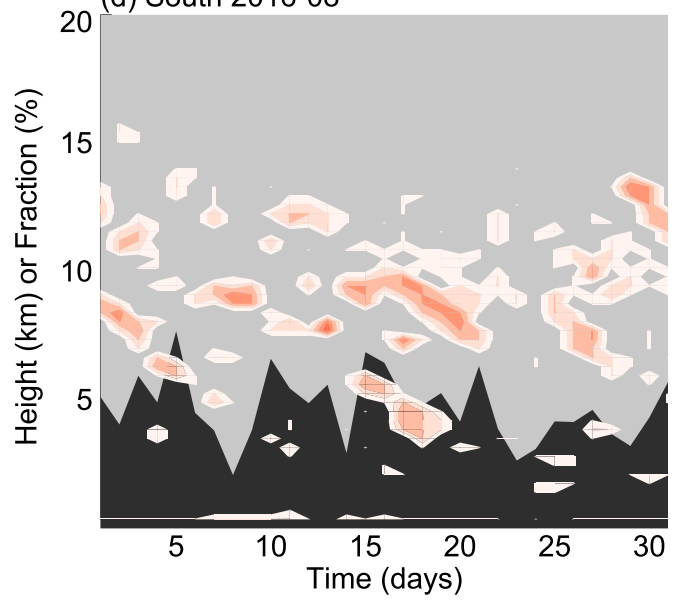

FIG. 5. Black shading shows the daily cloud-wave coupling index $\nu_{\text {coupl }}$. White to red colors mark the fraction of ground-based phase speeds in the interval -20 to $+20 \mathrm{~m} \mathrm{~s}^{-1}$ for which the critical wavelength [Eq. (3)] exceeds $30 \mathrm{~km}$.

pronounced than in the North domain; large correlations are also seen for zonal winds at $10-15$ and $15-20 \mathrm{~km}$, as well as for correlations with $\nu_{\text {trap. }}$. Note, however, that the winds at different levels are mutually correlated in Fig. 4b, which limits our ability to conclude which level is physically responsible for the trapping. We will return to this question in the following section. In August there are no notable relationships between $A_{\text {trap }}$ or $\nu_{\text {trap }}$ and the background wind.

These findings are in line with the fact that an influence of the winds on $\lambda_{w}^{p}$ was also limited to December. So far, the results suggest that stronger westerly winds in December are associated with a decreasing Scorer parameter (Fig. 3), which corresponds to an increasing critical wavelength $\lambda_{x}^{*}$, and more trapping.
Next, we investigate if these seasonal variations are reflected in the cloud field.

\section{c. Cloud-wave coupling in simulations}

To quantify the relationship between trapped waves and cloudiness, we perform a cross-spectral analysis of the vertical velocity and the vertically integrated cloud water, and derive the daily cloud coupling index $\nu_{\text {coupl }}$ in appendix section c. This index is only a function of time because we average over the two reference levels and all spectral components. The index is a measure of the occurrence of trapped waves paired with strong covariability of the vertical velocity and cloud field. In other words, large $\nu_{\text {coupl }}$ indicates days when trapped waves are present and the 

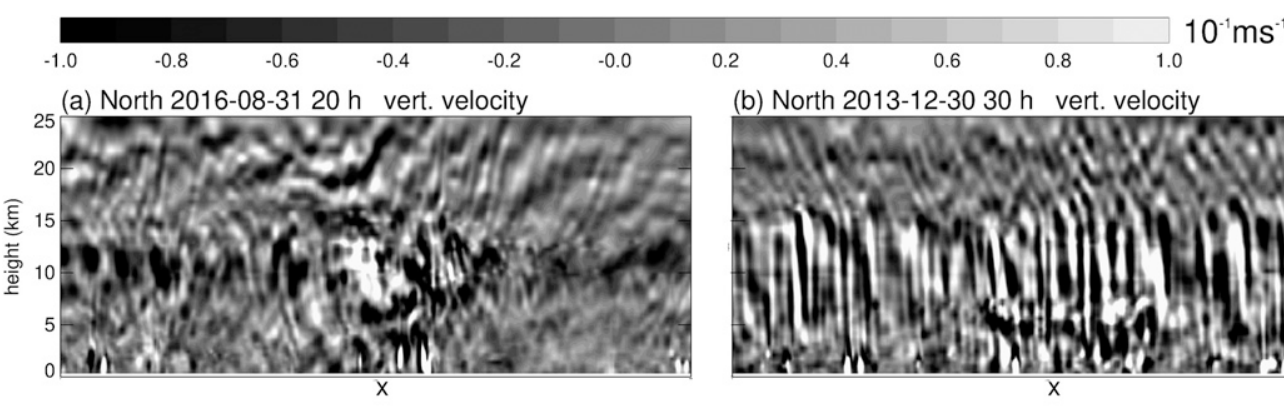

(b) North 2013-12-30 $30 \mathrm{~h}$ vert. velocity
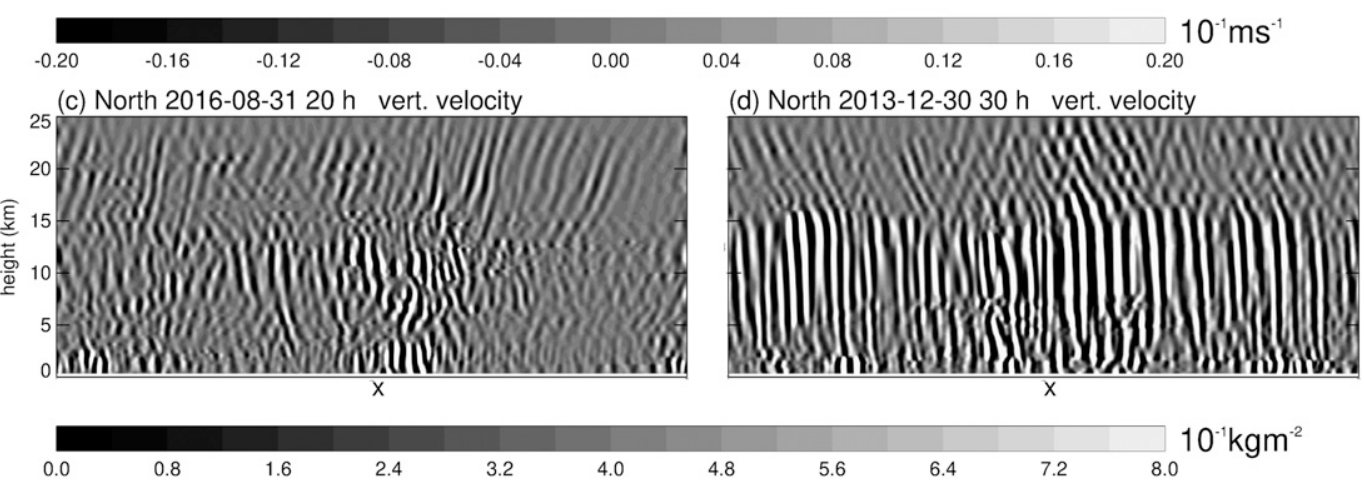

(e) North 2016-08-3120 h cloud water

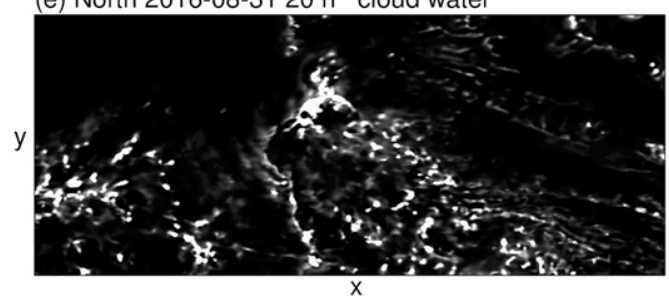

(f) North 2013-12-30 $30 \mathrm{~h}$ cloud water

FIG. 6. Cross sections for the days of maximum $\nu_{\text {coupl }}$. Shown is the time of maximum hourly $\nu_{\text {coupl }}$ on the respective days. (a)-(d) $x-z$ cross sections of vertical velocity through the center of the domain. The data in (a) and (b) are unfiltered fields, those in (c) and (d) are zonally filtered to $12 \leq \lambda_{x} \leq 30 \mathrm{~km}$. (e),(f) Horizontal maps of the entire North domain, which spans $1000 \mathrm{~km}$ in the zonal direction and $500 \mathrm{~km}$ in the meridional direction. Hours shown above each panel are relative to the initialization of the simulation, which is 0000 UTC on the dates shown above the panels.

cloud field has similar spectral properties as the trapped waves.

Like the peak wavelength, $\lambda_{w}^{p}$, the trapping amplitude $\left.A_{\text {trap }}\right|_{z_{\text {ref }}, \lambda_{x}}$ and the trapping frequency $\left.\nu_{\text {trap }}\right|_{z_{\text {ref }}, \lambda_{x}}$, which are quantities based on the vertical wind velocity alone, $\nu_{\text {coupl }}$ is also correlated with the large-scale wind in December, but not in August (Table 2). Cloud-wave coupling is more frequent when westerly winds increase at $5-10 \mathrm{~km}$ in the North domain. In the South domain there is sensitivity to winds across $5-20 \mathrm{~km}$, as was the

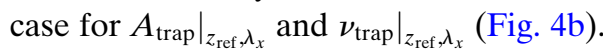

Figure 5 shows the temporal evolution of the cloudwave coupling index $\nu_{\text {coupl }}$ (dark shading). The value of $\nu_{\text {coupl }}$ is more variable in December than in August and there is evidence that this modulation is driven by changes in the background wind. Colors enclose times and heights where the critical wavelength $\lambda_{x}^{*}$ is greater than $30 \mathrm{~km}$ [Eq. (3)] for at least $10 \%$ of the ground-based phase speeds in the interval -20 to $+20 \mathrm{~m} \mathrm{~s}^{-1}$ [recall that the Scorer parameter depends on the ground-based phase speed; Eq. (2)]. These are times when theory predicts trapping. $30 \mathrm{~km}$ is chosen as the greatest $\lambda_{x}$ value considered here. Figures $5 \mathrm{a}$ and $5 \mathrm{~b}$ confirm a good match of coupling days (large $\nu_{\text {coupl }}$ ) and days for which large-scale conditions are conducive to trapping (reddish areas). For a ground-based phase speed of $0 \mathrm{~m} \mathrm{~s}^{-1}$, for example, $\nu_{\text {coupl }}$ is negatively correlated with the Scorer parameter averaged over $5-10 \mathrm{~km}$ in the North domain and $10-15 \mathrm{~km}$ in the South domain (Table 2). In August, we do not find such correlations (Table 2). Hardly any waves are predicted to be trapped in August in the North domain (Fig. 5c). In the South domain trapping could occur in August, but it would occur in the lower or midtroposphere. 

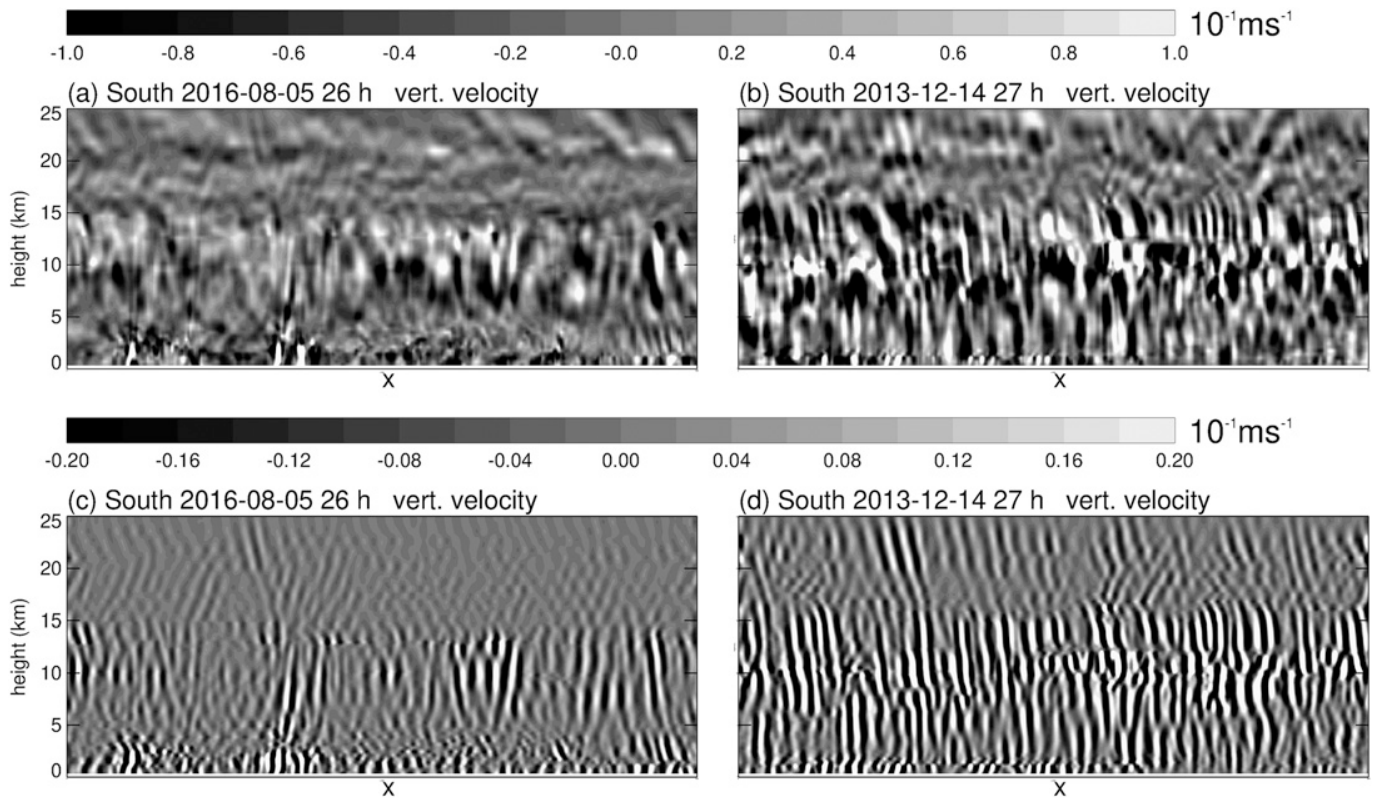

(d) South 2013-12-1427 h vert. velocity
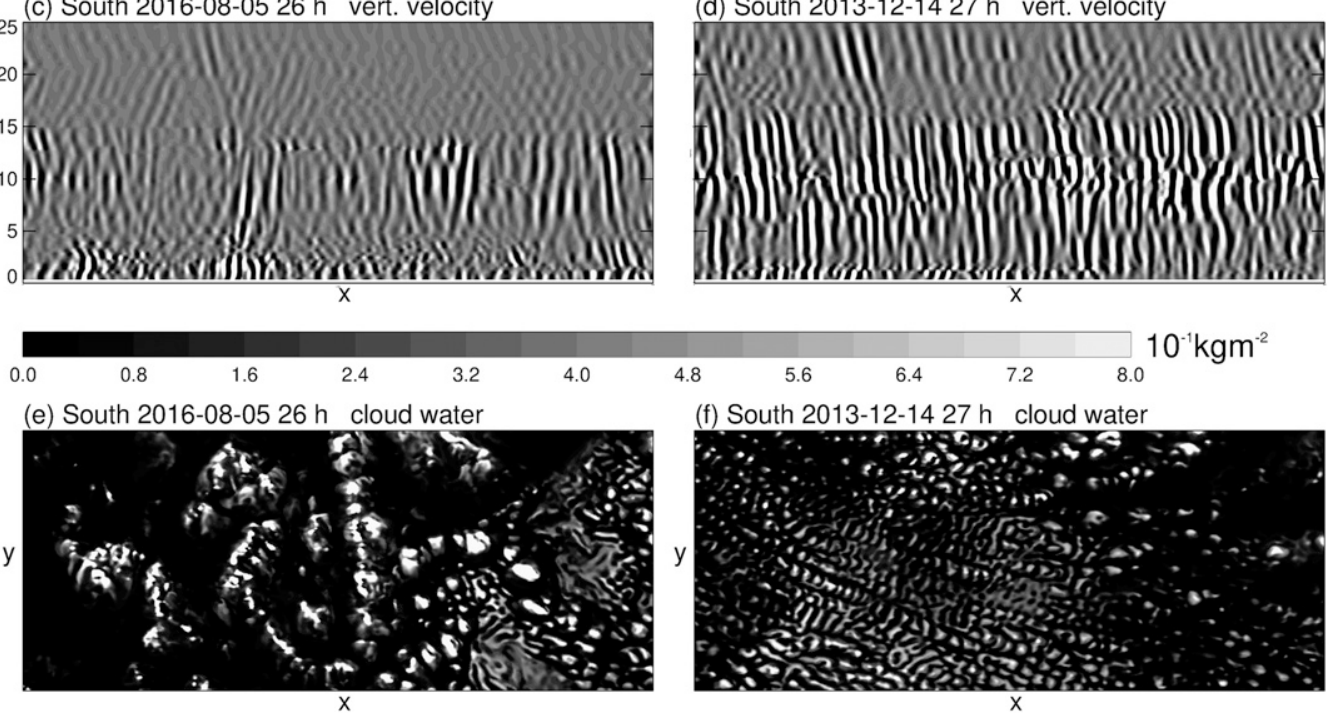

FIG. 7. As in Fig. 6, but for the South domain.

\section{d. Signatures of trapped waves}

The signature of cloud-wave coupling in vertical velocity patterns and vertically integrated cloud water, called the "cloud field" for simplicity, is next examined in snapshots from simulations and observations of the strongest days of $\nu_{\text {coupl }}$.

\section{1) THE SIMUlated CLOUd FIELD}

The days of maximum $\nu_{\text {coupl }}$ are 31 August 2016 and 30 December 2013 for the North domain (dates denote the day of initialization). On 30 December 2013 vertically aligned periodic up- and downward motions indicative of trapped GWs prevail across the domain (Fig. 6b), as in previous idealized simulations (Lane and Clark 2002). The figure shows the cross section through the middle (in $y$ direction) of the domain. Figure $6 \mathrm{~d}$ confirms that the periodic pattern is found in the spectral range $12 \leq \lambda_{x} \leq 30 \mathrm{~km}$. In the stratosphere, above the wave duct, the phase lines are clearly tilted, indicating propagating waves. Given the large value of $N^{2}$ in the stratosphere, waves are almost always able to propagate inside the stratosphere. The vertical structure is consistent with the heights where $\lambda_{x}^{*}>30 \mathrm{~km}$ in Fig. 5a on 30 December 2013. According to Fig. 5a waves should be trapped below either about 14 or $8 \mathrm{~km}$ altitude. A close look at Figs. $6 \mathrm{~b}$ and $6 \mathrm{~d}$ shows that abrupt changes of the periodic structures appear at both levels. Finally, the cloud field in Fig. 6f is highly organized in a nearly spatially homogeneous pattern of broken clouds.

The situation on 31 August 2016 is different altogether. Neither is there a pronounced signal of trapped GWs in the vertical velocity field (Figs. 6a,c), nor is there a noteworthy pattern of organization in the cloud field (Fig. 6e). Note that this is the August day and hour with the largest $\nu_{\text {coupl }}$ index and nevertheless we cannot find evidence of any cloud-wave coupling. It provides qualitative support for the quantitative analysis summarized in Fig. 5c. August background conditions in the North domain are not conducive to trapping.

Figure 7 repeats Fig. 6 but for the South domain. All of the above descriptions and conclusions apply to the 
(a) North 2013-12-30 cloud water

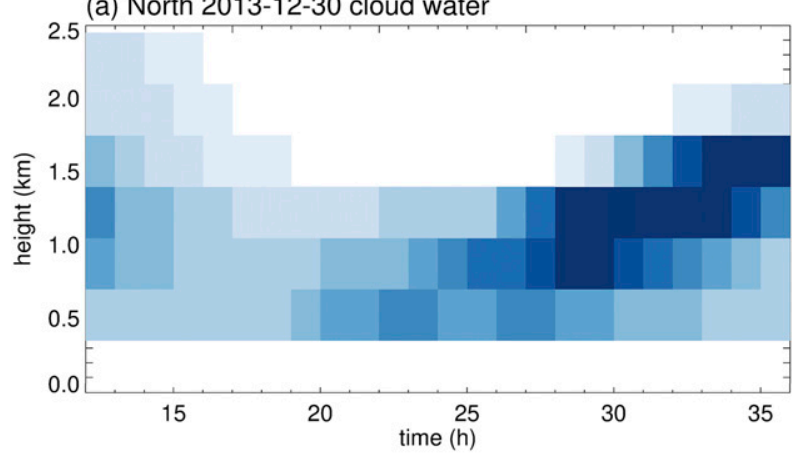

(b) South 2013-12-14 cloud water

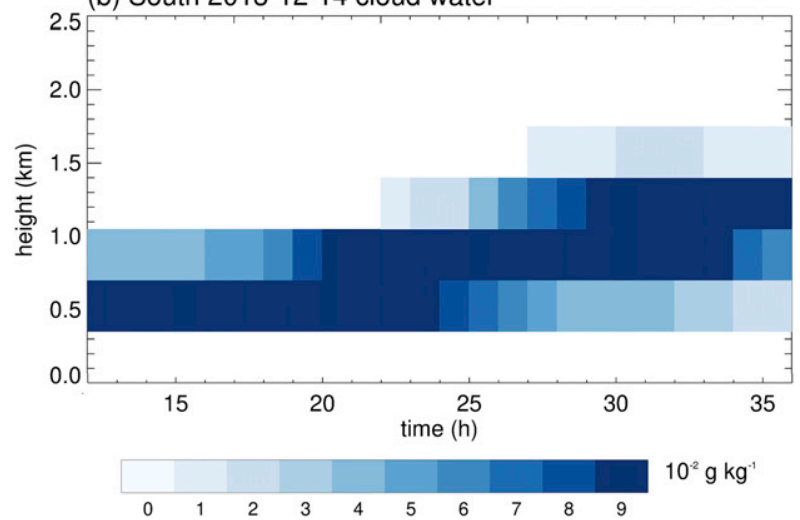

FIG. 8. (a) North and (b) South domain-mean cloud water as a function of time and height. Time is relative to the initialization of the simulation, which is 0000 UTC on the dates shown above the panels.

South domain, too. The cloud field in Fig. $7 \mathrm{f}$ shows an even more pronounced fingerprint of waves than Fig. $6 \mathrm{f}$. Meanwhile, the vertical velocity structures in Fig. $7 d$ suggest multiple reflecting layers. This is also consistent with Fig. 5b, which would point to trapping at about 7 , 11 , and $15 \mathrm{~km}$.

The clouds in Figs. 6f and $7 \mathrm{f}$ have tops below $1.8 \mathrm{~km}$ (Fig. 8). In the 30 December 2013 simulation in the North domain, and in the 14 December 2013 simulation in the South domain, cloud-base height and cloud-top height increase with time (Fig. 8). This is also reflected in a moistening of the $850 \mathrm{hPa}$ level: the domain averaged relative humidity is $91 \%$ at $36 \mathrm{~h}$ of simulation compared $79 \%$ at $12 \mathrm{~h}$ for the North domain, and $80 \%$ at $36 \mathrm{~h}$ of simulation compared $45 \%$ at $12 \mathrm{~h}$ for the South domain. The corresponding relative humidity changes averaged over all days are -1.6 (North) and +2.4 (South) percent points. To test whether there is a statistically significant relationship between cloud-wave coupling and moistening we compute the linear correlation coefficient between $\nu_{\text {coupl }}$ and the increase of $850 \mathrm{hPa}$ domain-averaged relative humidity, using the 12 days of the strongest $\nu_{\text {coupl }}$. The correlation coefficients are 0.4 (North; $p$ value $=0.19$ ) and 0.9 (South; $p$ value $\left.<10^{-4}\right)$. This suggests that trapped waves may contribute to a deepening of shallow clouds.

\section{2) SignAtURES OF TRAPPED WAVES IN SATELLITE IMAGERY}

As the simulations were initialized daily from analyzed data, the large-scale circulation is realistic and we should expect trapped GWs to be present in reality on days that were identified as trapping days in the simulations. The visible satellite images in Figs. 9 and 10 show areas of the same size and nearly the same location as the North domain during the period of the greatest cloud-wave coupling index $\nu_{\text {coupl }}$. Compared to the simulation the observed cloud field is more complicated

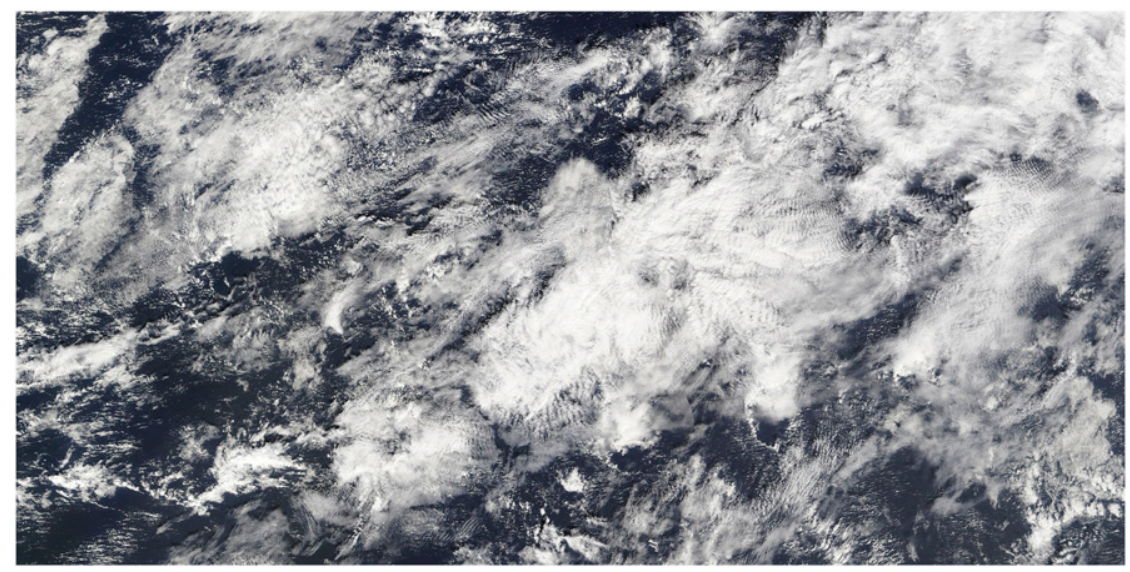

FIG. 9. True-color image of the MODIS imager on board the Terra satellite. The image is from the descending Terra overpass at 1255 UTC 31 Dec 2013 . The region is $10^{\circ}-15^{\circ} \mathrm{N}, 55^{\circ}-$ $45^{\circ} \mathrm{W}$. This day is the strongest day of cloud-wave coupling in the North domain identified in the December simulation. The area shown in this image is identical to the North domain. 


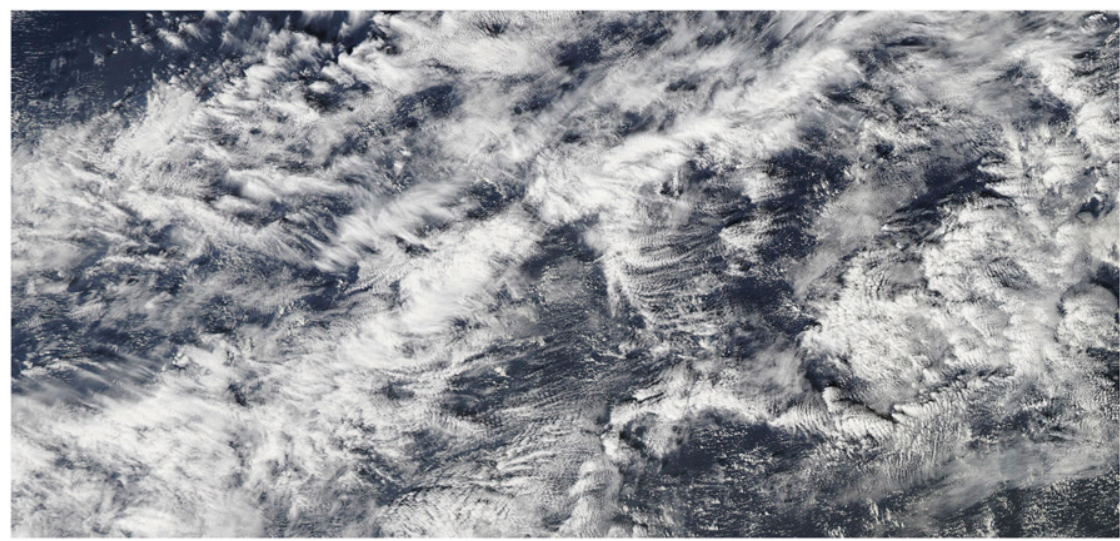

FIG. 10. True-color image of the MODIS imager on board the Aqua satellite. The image is from the ascending Aqua overpass at $1615 \mathrm{UTC} 31 \mathrm{Dec} 2013$. The region is $10^{\circ}-15^{\circ} \mathrm{N}, 50^{\circ}-40^{\circ} \mathrm{W}$. This is the day before the strongest day of cloud-wave coupling in the North domain identified in the December simulation. The area shown in this image is the same size as the North domain, but shifted eastward by $5^{\circ}$ relative to the North domain.

with multiple layers and cloud clusters of various sizes. Nevertheless, we can make out multiple wave trains in the cloud field that reveal the presence of short-lengthscale GWs. Their narrow spatial confinement and sharp edges distinguish them from horizontal convective rolls (HCRs; see, e.g., Figs. 1 and 2 in Brown 1980). Cloud patterns due to GWs and HCRs can show some resemblance in that both can be associated with closely spaced cloud lines. However, HCRs are closely aligned with the mean wind vector of the boundary layer, whereas cloud lines due to GWs form nearly perpendicular to the wind direction. In the simulation initialized on 30 December 2013 the average zonal wind below $1.75 \mathrm{~km}$ altitude at $12-36 \mathrm{~h}$ of simulations is $-9.9 \mathrm{~m} \mathrm{~s}^{-1}$, the meridional wind speed is $-2.0 \mathrm{~m} \mathrm{~s}^{-1}$. Thus, if GWs are the cause of the cloud lines, we would expect the clouds to align in the north-south direction with a small counterclockwise tilt. This is what the satellite image shows, and therefore we can be convinced that the lines are due to GWs rather than HCRs.

Waves are also visible in the satellite image on the day of the strongest cloud-wave coupling index in the South domain (Fig. 11). Particularly in the western portion of this image there are clear wave trains, forming isolated lines of clouds. In this case zonal and meridional winds are -7.8 and $+3.0 \mathrm{~m} \mathrm{~s}^{-1}$, respectively, which would correspond to alignment in the north-south direction, but with a substantial clockwise

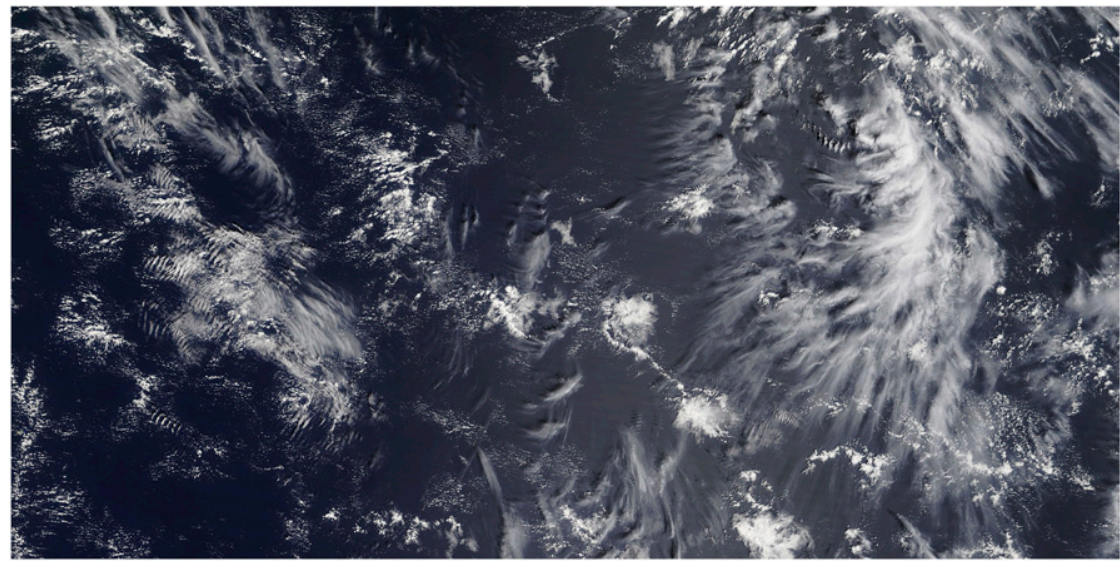

FIG. 11. True-color image of the MODIS imager on board the Terra satellite. The image is from the descending Terra overpass at 1220 UTC 15 Dec 2013 . The region is $5^{\circ}-0^{\circ} \mathrm{S}, 32.5^{\circ}-$ $22.5^{\circ} \mathrm{W}$. This day is the strongest day of cloud-wave coupling in the South domain identified in the December simulation. The area shown in this image is the same size as the South domain, but shifted westward by $2.5^{\circ}$ relative to the South domain. 
TABLE 3. Columns show the days of December 2013 sorted by their cloud-wave coupling index. The index is based on the time interval $12-36 \mathrm{~h}$ after initialization at 0000 UTC on the day listed. The index increases from top to bottom. Two tilde symbols indicate that wave trains are clearly visible and one tilde symbol indicates that weak wave trains exist somewhere in the images. On the remaining days, no wave trains are visible in the satellite images. The analysis is based on the true-color corrected-reflectance imagery from the MODIS instruments aboard the Terra and Aqua satellites, examples of which are shown in Figs. 9, 10, and 11. Only the area inside the North (column 1) and South (column 2) domain was considered.

\begin{tabular}{|c|c|c|c|}
\hline \multicolumn{2}{|c|}{ December 2013 North } & \multicolumn{2}{|c|}{ December 2013 South } \\
\hline & 2 & & 4 \\
\hline \multirow{10}{*}{$\sim \sim$} & 1 & & 7 \\
\hline & 11 & & 5 \\
\hline & 4 & & 3 \\
\hline & 19 & & 29 \\
\hline & 20 & & 30 \\
\hline & 3 & & 6 \\
\hline & 10 & & 8 \\
\hline & 12 & & 9 \\
\hline & 17 & & 27 \\
\hline & 18 & $\sim$ & 1 \\
\hline \multirow[t]{6}{*}{$\sim \sim$} & 26 & & 2 \\
\hline & 15 & & 11 \\
\hline & 21 & & 25 \\
\hline & 16 & & 28 \\
\hline & 13 & & 22 \\
\hline & 14 & & 10 \\
\hline$\sim \sim$ & 27 & & 12 \\
\hline \multirow[t]{4}{*}{$\sim \sim$} & 24 & & 21 \\
\hline & 9 & & 23 \\
\hline & 25 & & 26 \\
\hline & 5 & & 31 \\
\hline$\sim \sim$ & 28 & & 24 \\
\hline$\sim \sim$ & 29 & & 13 \\
\hline$\sim \sim$ & 23 & $\sim$ & 17 \\
\hline$\sim \sim$ & 8 & & 20 \\
\hline$\sim \sim$ & 31 & $\sim \sim$ & 19 \\
\hline$\sim \sim$ & 7 & $\sim \sim$ & 16 \\
\hline$\sim \sim$ & 6 & & 18 \\
\hline$\sim$ & 22 & $\sim \sim$ & 15 \\
\hline$\sim \sim$ & 30 & $\sim \sim$ & 14 \\
\hline
\end{tabular}

tilt. This predicted angle is also in perfect agreement with the satellite image.

For completeness, Table 3 lists for all simulated dates whether GW signatures are visible in the satellite images. We evaluated each image blindly, i.e., without knowledge of either date or cloud-wave coupling index. Repeating this procedure three times on computer screens of different sizes and with or without zooming in gave the same results. The dates in Table 3 are ordered by the magnitude of the cloud-wave coupling index and there is a clear correspondence between visible wave signatures and predictions of strong cloud-wave coupling days in winter. We also browsed the satellite images for August 2016 for both domains. With the exception of one day (16 August 2016) in the South domain, these do not show any significant GW signatures. The satellite data thus provide further qualitative support for our analysis.

\section{Discussion and conclusions}

The wavelengths seen in the satellite images are mostly shorter than those in the simulations, sometimes less than $5 \mathrm{~km}$. The simulations would not be able to resolve such short waves. Figure 12 compares the cloud fields shown in Fig. 6 between the $2.5 \mathrm{~km}$ simulation and an additional nested simulation at $1.25 \mathrm{~km}$ horizontal resolution. Figure 12 shows that individual clouds in the $2.5 \mathrm{~km}$ simulation split into multiple clouds at the $1.25 \mathrm{~km}$ horizontal resolution, even though the large-scale structure of the cloud field remains similar. Deficiencies in the parameterization of unresolved scales, such as microphysics and turbulence, as well as the chaotic evolution of the system, make it hard to believe that the satellite-observed cloud fields could be matched even if the horizontal resolution were reduced to the order of $100 \mathrm{~m}$. Such a match, however, was not our goal. Instead, the comparison to observations serves to demonstrate that the phenomena of wave trapping and wave imprints on the cloud field occur in reality and are also captured by simulations of full complexity at resolutions of a few kilometers. Additional studies based on observations and large-eddy model simulations are required to bridge the gap between nature and kilometerresolution models to further address the importance of cloud-wave coupling on the overall cloud amount and redistribution of moisture, and their accurate simulation in the newest generation of GCMs.

This study examined the variability of trapped gravity waves (GWs) inside two regions that are located in the trade wind regime of the tropical Atlantic. Using spectral analysis, trapped GWs and their coupling to the cloud field were studied in large subdomains $(1000 \mathrm{~km} \times$ $500 \mathrm{~km})$ spanned by a fine $(2.5 \mathrm{~km})$ numerical mesh of simulations covering one month of August and one month of December. The large-scale background winds in the two regions have a pronounced seasonal cycle. December conditions with strong zonal wind shear in the free troposphere are more conducive to trapping than August conditions when vertical variations of the wind are weak. The coupling between clouds and trapped GWs is sufficiently strong to be detectable in these simulations of full complexity. In December stronger upper-tropospheric westerly winds are associated with more frequent and stronger trapping, as well as with a stronger coupling between the trapped waves and the 


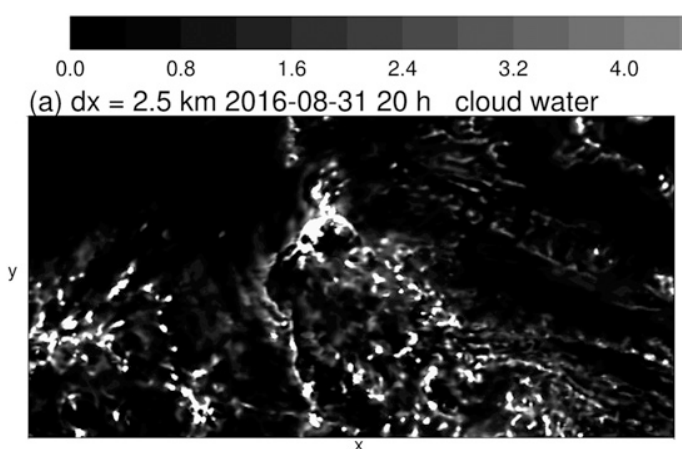

(c) $\mathrm{dx}=1.25 \mathrm{~km} 2016-08-3120 \mathrm{~h}$ cloud water

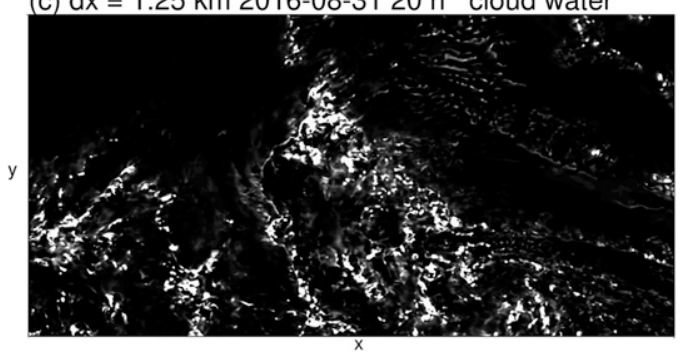

$\begin{array}{lllll}4.8 & 5.6 & 6.4 & 7.2 & 8.0\end{array}$

(b) $\mathrm{dx}=2.5 \mathrm{~km} 2013-12-3030 \mathrm{~h}$ cloud water

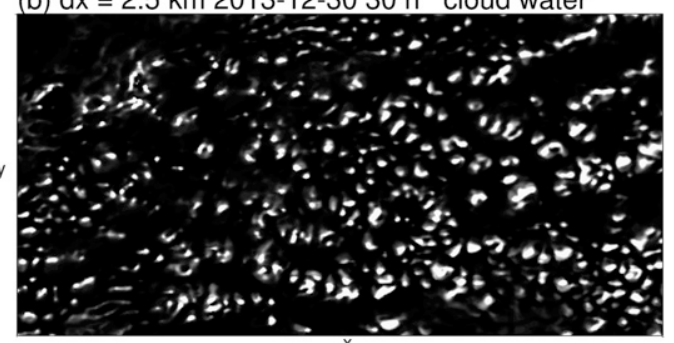

(d) $\mathrm{dx}=1.25 \mathrm{~km} 2013-12-3030 \mathrm{~h}$ cloud water

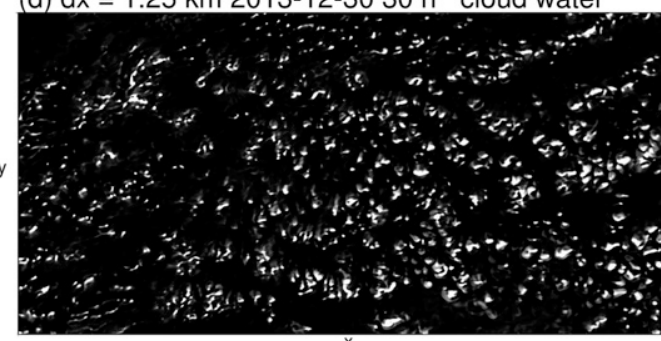

FIG. 12. Horizontal maps of the entire North domain, which spans $1000 \mathrm{~km}$ in the zonal direction and $500 \mathrm{~km}$ in the meridional direction. Hours shown above each panel are relative to the initialization of the simulation, which is 0000 UTC on the dates shown above the panels. (a),(b) From a simulation with a horizontal resolution of $2.5 \mathrm{~km}$. (c),(d) From a simulation with a horizontal resolution of $1.25 \mathrm{~km}$.

cloud field. In the simulations this results in a highly organized scattered cloud field with cloud spacings of about $19 \mathrm{~km}$, matching the dominant trapped GW wavelength. Satellite scenes of the days that were identified as strong cloud-wave coupling days based on the simulations also show an imprint of GWs on the cloud field. The observed cloud fields are more complicated than those in the simulations in the sense that they display a greater variety of different cloud patterns. Yet, satellite imagery also suggests that trapped GWs occur more frequently in December than in August.

This study is the first, to our knowledge, to provide evidence that trapped waves modulate the observed as well as the simulated cloud field in simulations of full complexity, and in ways that are predictable based on the large-scale circulation. Global simulations at resolutions on the order of $2.5 \mathrm{~km}$ are opening new horizons in climate modeling (Satoh et al. 2019). Therefore, it is important to understand the dynamic coupling between GWs and cloud processes in these simulations. The importance of trapped GWs for organizing clouds in the real atmosphere was not assessed here, but it is clear that trapped waves would distribute energy and momentum throughout the troposphere. Theory and the evidence provided here suggest that these waves have a seasonal cycle in reality as well. Future studies should further evaluate the relevance of the interactions between clouds and trapped GWs for determining cloud properties based on observations and test their realism in convectionpermitting global simulations. We here showed that clouds can be patterned by waves. Important remaining questions are whether or not such interactions affect the overall amount of cloudiness, favor deeper clouds, or influence cloud lifetime, as suggested by idealized studies (Balaji and Clark 1988). All of these factors are relevant for weather and climate modeling.

Acknowledgments. CCS was supported by the Minerva Fast Track Program of the Max Planck Society. She is grateful to Prof. Todd P. Lane for helpful discussions. CCS acknowledges the use of imagery from the NASA Worldview application (https:// worldview.earthdata.nasa.gov), part of the NASA Earth Observing System Data and Information System (EOSDIS).

\section{APPENDIX}

\section{Mathematical Derivations}

\section{a. Peak wavelengths}

For all times $t$, all vertical levels $z$ and all latitudinal points $y^{\prime}$ within the North and South domains, we compute the S-transformation $\mathrm{ST}_{w}\left(x^{\prime}, \lambda_{x}^{\prime}\right)$ of the vertical velocity $w$ as function of $x^{\prime}$ and the zonal wavelength 
$\lambda_{x}^{\prime}$. The primed coordinates $x^{\prime}$ and $y^{\prime}$ correspond to the $0.025^{\circ} \times 0.025^{\circ}$ resolution; $x^{\prime}$ spans 400 points $(1000 \mathrm{~km})$ and $y^{\prime} 200$ points $(500 \mathrm{~km})$. By weighting $\lambda_{x}^{\prime}$ with the spectral power $\left.\left|\mathrm{ST}_{w}\left(x^{\prime}, \lambda_{x}^{\prime}\right)\right|_{z}\right|^{2}$ and averaging over all $y^{\prime}$ and each day, we derive the daily peak zonal wavelength of the vertical wind $\lambda_{w}^{p}$ at level $z$. An analogous calculation is performed on vertically integrated cloud water to obtain the daily peak zonal wavelength of the cloud field $\lambda_{c}^{p}$.

\section{b. Trapping fraction and trapping amplitude}

We carry out the following computational steps for the North and South domains. We compute the crossspectrum of vertical velocity spectra

$$
\left.\operatorname{cross}\left(x^{\prime}, \lambda_{x}^{\prime}\right)\right|_{z, z_{\text {ref }}}=\left.\operatorname{ST}_{w}\left(x^{\prime}, \lambda_{x}^{\prime}\right)\right|_{z} \times\left.\operatorname{ST}_{w}^{*}\left(x^{\prime}, \lambda_{x}^{\prime}\right)\right|_{z_{\text {ref }}} \forall t, y^{\prime}, z
$$

with respect to two reference levels $z_{\text {ref }} \in\{3.5,7.0\} \mathrm{km}$. $\mathrm{ST}^{*}$ is the complex conjugate of ST. The covarying amplitude is

$$
\left.\operatorname{cov}\left(x^{\prime}, \lambda_{x}^{\prime}\right)\right|_{z, z_{\text {ref }}}=\sqrt{\left|\operatorname{cross}\left(x^{\prime}, \lambda_{x}^{\prime}\right)\right|} \forall t, y^{\prime}, z
$$

and the phase difference is obtained from the real and imaginary components of the cross-spectrum,

$$
\left.\phi\left(x^{\prime}, \lambda_{x}^{\prime}\right)\right|_{z, z_{\mathrm{ref}}}=\tan ^{-1}\left(\frac{\Im \operatorname{cross}\left(x^{\prime}, \lambda_{x}^{\prime}\right)}{\Re \operatorname{cross}\left(x^{\prime}, \lambda_{x}^{\prime}\right)}\right) \forall t, y^{\prime}, z .
$$

For $\phi>45^{\circ}$, we set $\operatorname{cov}\left(x^{\prime}, \lambda_{x}^{\prime}\right)=0$. A nonzero threshold for $\phi$ is required because wave refraction may alter the horizontal wavelength of a wave [see, e.g., Hasha et al. (2008) for equations]. A phase shift of $45^{\circ}$ would occur if a wave of typical horizontal wavelength $(19 \mathrm{~km}$; Table 1$)$, were shifted by one horizontal grid point, and thus is a sensible choice for a threshold. With a nonzero threshold, it is likely that some waves are falsely classified as trapped. For this reason, we will only consider relative differences in derived quantities and use Spearman's rank correlations, as such measures are largely insensitive to constant offsets.

Last, we perform the following steps of regridding. An evenly spaced horizontal wavelength grid is defined by $\lambda_{x} \in\{12,14,16,18,20,22,24,26,28,30\} \mathrm{km}$, with wavelength-dependent bin widths of $\Delta \lambda_{x}=0.1 \lambda_{x}$. These wavelengths are chosen to accommodate the spectral peaks (Table 1). Since the shortest wavelength of this grid, $12 \mathrm{~km}$, is still greater than 4 times the original horizontal resolution of the data, we average over $\Delta x=10 \mathrm{~km}$ in the zonal direction. It is also reasonable to assume that a wave is present across at least two neighboring grid points in the meridional direction. Therefore, to increase robustness and decrease the amount of data, we also average over $\Delta y=5 \mathrm{~km}$. The unprimed quantities $x, y$, and $\lambda_{x}$ denote this coarsened coordinate system.

We treat the gridded phase difference $\phi$ as a fivedimensional quantity,

$$
\phi=\phi\left(x, y, z, z_{\text {ref }}, \lambda_{x}\right) .
$$

Based on $\phi$ we define the trapping index $I_{\text {trap }}$ :

$$
\begin{aligned}
I_{\text {trap }}\left(x, y, z, z_{\text {ref }}, \lambda_{x}\right)= & 1 \mid \phi\left(x, y, z, z_{\text {ref }}, \lambda_{x}\right) \leq 45^{\circ} \\
& \text { for at least } 12 \text { of } 16 \text { levels } \\
= & 0 \mid \text { else or if it rained, }
\end{aligned}
$$

where the 16 levels are at $2100 \leq z \leq 7350 \mathrm{~m}$. The reason for setting $I_{\text {trap }}=0$ in locations with rainfall during the past hour is to avoid a contamination of the index by strong updrafts. In principle, this rain mask could be based on instantaneous rainfall, but the model output contains only rainfall accumulation.

For the covarying amplitude we perform the same regridding and then average over the 16 vertical levels between $2100 \leq z \leq 7350 \mathrm{~m}$. The resulting trapping amplitude $a_{\text {trap }}$ is characteristic of the free troposphere and has the same dimensions as $I_{\text {trap }}$. Since the interest is only in instances of trapping, we further set

$$
\begin{gathered}
a_{\text {trap }}=a_{\text {trap }}\left(x, y, z_{\text {ref }}, t, \lambda_{x}\right)=0 \quad \text { if } \\
I_{\text {trap }}\left(x, y, z_{\text {ref }}, t, \lambda_{x}\right)=0 .
\end{gathered}
$$

By averaging $a_{\text {trap }}$ and $I_{\text {trap }}$ over the domain, we obtain the average covarying amplitude $A_{\text {trap }}\left(z_{\text {ref }}, t, \lambda_{x}\right)$ and the trapping fraction $\nu_{\text {trap }}\left(z_{\text {ref }}, t, \lambda_{x}\right)$, respectively.

\section{c. Cloud-wave coupling index}

We compute the cross correlation of the verticalvelocity spectrum $\mathrm{ST}_{w}\left(x^{\prime}, \lambda_{x}^{\prime}\right)$ at each reference level $z_{\text {ref }}$ with the corresponding spectrum of the vertically integrated cloud water $\mathrm{ST}_{c}\left(x^{\prime}, \lambda_{x}^{\prime}\right)$,

$$
\left.\operatorname{cross}\left(x^{\prime}, \lambda_{x}^{\prime}\right)\right|_{z_{\text {ref }}}=\operatorname{ST}_{c}\left(x^{\prime}, \lambda_{x}^{\prime}\right) \times\left.\operatorname{ST}_{w}^{*}\left(x^{\prime}, \lambda_{x}^{\prime}\right)\right|_{z_{\text {ref }}} \forall t, y^{\prime} .
$$

The covarying amplitude is

$$
\left.\operatorname{cov}\left(x^{\prime}, \lambda_{x}^{\prime}\right)\right|_{z_{\text {ref }}}=\sqrt{\left|\operatorname{cross}\left(x^{\prime}, \lambda_{x}^{\prime}\right)\right|_{z_{\text {ref }}} \mid} \forall t, y^{\prime} .
$$

Regridding cov like $I_{\text {trap }}$ gives $a_{\text {coupl }}\left(x, y, z_{\text {ref }}, t, \lambda_{x}\right)$. For the covariation of the vertical velocity with the cloud field we do not pay attention to the phase, because clouds and waves are allowed and expected to move 
relative to each other (Balaji and Clark 1988). As long as they have a common wavelength, the wave field would favor clouds to form at a similar distance as existing clouds.

To relate $a_{\text {coupl }}$ to day-to-day changes in the large-scale circulation, we again define a daily index. For each $z_{\text {ref }}$ and each $\lambda_{x}$ separately, we compute the standard devia-

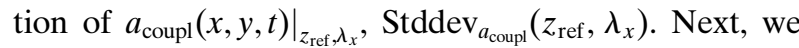
compute the fraction of the $x-y$ domain, $\left.F_{\text {coupl }}(t)\right|_{z_{\text {ref }}, \lambda_{x}}$, where $\left.a_{\text {coupl }}(x, y, t)\right|_{z_{\text {ref }}, \lambda_{x}}>0.8 \cdot \operatorname{Stddev}_{a_{\text {coupl }}}\left(z_{\text {ref }}, \lambda_{x}\right)$ while in addition $\left.I_{\text {trap }}(x, y, t)\right|_{z_{\text {ref }}, \lambda_{x}}=1$. (Strictly, we compute the residual fraction of the domain, as areas of rainfall are still excluded.) This fraction $\left.F_{\text {coupl }}(t)\right|_{z_{\text {ref }}, \lambda_{x}}$ is a function of time and describes the occurrence of trapping paired with strong covariability of the vertical velocity and cloud field outside of areas where there is rainfall. $\left.F_{\text {coupl }}(t)\right|_{z_{\text {ref }}, \lambda_{x}}$ is then averaged over the two reference levels, the 10 horizontal wavelengths, and over each day to obtain the index of cloud-wave coupling $\nu_{\text {coupl }}$. The averaging over all wavelengths and the two reference heights is justified based on Fig. 4.

\section{REFERENCES}

Alexander, M. J., and Coauthors, 2008: Global estimates of gravity wave momentum flux from High Resolution Dynamics Limb Sounder observations. J. Geophys. Res., 113, D15S18, https:// doi.org/10.1029/2007JD008807.

Balaji, V., and T. L. Clark, 1988: Scale selection in locally forced convective fields and the initiation of deep cumulus. J. Atmos. Sci., 45, 3188-3211, https://doi.org/10.1175/1520-0469(1988) $045<3188$ :SSILFC $>2.0$.CO;2.

__, J.-L. Redelsperger, and G. P. Klaassen, 1993: Mechanisms for the mesoscale organization of tropical cloud clusters in GATE phase III. Part I. Shallow cloud bands. J. Atmos. Sci., 50, 3571-3589, https://doi.org/10.1175/1520-0469(1993)050<3571: MFTMOO $>2.0 . \mathrm{CO} ; 2$.

Bony, S., and B. Stevens, 2019: Measuring area-averaged vertical motions with dropsondes. J. Atmos. Sci., 76, 767-783, https:// doi.org/10.1175/JAS-D-18-0141.1.

—_, and Coauthors, 2015: Clouds, circulation and climate sensitivity. Nat. Geosci., 8, 261-268, https://doi.org/10.1038/ ngeo2398.

Boucher, O., and Coauthors, 2013: Clouds and aerosols. Climate Change 2013: The Physical Science Basis, T. F. Stocker et al., Eds., Cambridge University Press, 571-657, https://doi.org/ 10.1017/CBO9781107415324.016.

Brown, R. A., 1980: Longitudinal instabilities and secondary flows in the planetary boundary layer: A review. Rev. Geophys., 18, 683-697, https://doi.org/10.1029/RG018i003p00683.

Cess, R. D., 1976: Climate change: An appraisal of atmospheric feedback mechanisms employing zonal climatology. J. Atmos. Sci., 33, 1831-1843, https://doi.org/10.1175/1520-0469(1976) $033<1831$ :CCAAOA $>2.0 . \mathrm{CO} ; 2$.

Clark, T. L., T. Hauf, and J. P. Kuettner, 1986: Convectively forced internal gravity waves: Results from two-dimensional numerical experiments. Quart. J. Roy. Meteor. Soc., 112, 899925, https://doi.org/10.1002/qj.49711247402.

Coppin, D., and S. Bony, 2018: On the interplay between convective aggregation, surface temperature gradients, and climate sensitivity. J. Adv. Model. Earth Syst., 10, 3123-3138, https:// doi.org/10.1029/2018MS001406.

Fritts, D. C., D. Janches, H. Iimura, W. K. Hocking, J. V. Bageston, and N. M. P. Leme, 2012: Drake Antarctic Agile Meteor Radar first results: Configuration and comparison of mean and tidal wind and gravity wave momentum flux measurements with Southern Argentina Agile Meteor Radar. J. Geophys. Res., 117, D02105, https://doi.org/10.1029/ 2011JD016651.

Gumley, L., J. Descloitres, and J. Schmaltz, 2010: Creating reprojected true color MODIS images: A tutorial. NASA Rep., 17 pp., https://cdn.earthdata.nasa.gov/conduit/upload/ 946/MODIS_True_Color.pdf.

Hasha, A., O. Bühler, and J. Scinocca, 2008: Gravity wave refraction by three-dimensionally varying winds and the global transport of angular momentum. J. Atmos. Sci., 65, 2892-2906, https://doi.org/10.1175/2007JAS2561.1.

Hauf, T., and T. L. Clark, 1989: Three-dimensional numerical experiments on convectively forced internal gravity waves. Quart. J. Roy. Meteor. Soc., 115, 309-333, https://doi.org/10.1002/qj.49711548606.

Klocke, D., M. Brueck, C. Hohenegger, and B. Stevens, 2017: Rediscovery of the doldrums in storm-resolving simulations over the tropical Atlantic. Nat. Geosci., 10, 891-896, https:// doi.org/10.1038/s41561-017-0005-4.

Lane, T. P., and T. L. Clark, 2002: Gravity waves generated by the dry convective boundary layer: Two-dimensional scale selection and boundary-layer feedback. Quart. J. Roy. Meteor. Soc., 128, 1543-1570, https://doi.org/10.1002/qj.200212858308.

LeMone, M. A., and R. J. Meitin, 1984: Three examples of fairweather mesoscale boundary-layer convection in the tropics. Mon. Wea. Rev., 112, 1985-1998, https://doi.org/10.1175/15200493(1984)112<1985:TEOFWM > 2.0.CO;2.

Nappo, C. J., 2002: An Introduction to Atmospheric Gravity Waves. Academic Press, 276 pp.

Satoh, M., B. Stevens, F. Judt, M. Khairoutdinov, S.-J. Lin, W. M. Putman, and P. Düben, 2019: Global cloud-resolving models. Curr. Climate Change Rep., 5, 172-184, https://doi.org/10.1007/ s40641-019-00131-0.

Soden, B. J., and G. A. Vecchi, 2011: The vertical distribution of cloud feedback in coupled ocean-atmosphere models. Geophys. Res. Lett., 38, L12704, https://doi.org/10.1029/2011GL047632.

Stephan, C. C., M. J. Alexander, M. Hedlin, C. D. de Groot-Hedlin, and L. Hoffmann, 2016: A case study on the far-field properties of propagating tropospheric gravity waves. Mon. Wea. Rev., 144, 2947-2961, https://doi.org/10.1175/MWR-D-16-0054.1.

Stevens, B., and Coauthors, 2016: The Barbados Cloud Observatory: Anchoring investigations of clouds and circulation on the edge of the ITCZ. Bull. Amer. Meteor. Soc., 97, 787-801, https:// doi.org/10.1175/BAMS-D-14-00247.1.

Stockwell, R. G., L. Mansinha, and R. P. Lowe, 1996: Localization of the complex spectrum: the S transform. IEEE Trans. Signal Process., 44, 998-1001, https://doi.org/10.1109/78.492555.

Wang, L., M. J. Alexander, T. B. Bui, and M. J. Mahoney, 2006: Small-scale gravity waves in ER-2 MMS/MTP wind and temperature measurements during CRYSTAL-FACE. Atmos. Chem. Phys., 6, 1091-1104, https://doi.org/10.5194/acp-6-1091-2006.

Wright, C. J., and J. C. Gille, 2013: Detecting overlapping gravity waves using the S-transform. Geophys. Res. Lett., 40, 18501855, https://doi.org/10.1002/grl.50378.

Zhao, M., 2014: An investigation of the connections among convection, clouds, and climate sensitivity in a global climate model. J. Climate, 27, 1845-1862, https://doi.org/10.1175/JCLID-13-00145.1. 